\title{
Causes of irritant contact dermatitis after occupational skin exposure: a systematic review
}

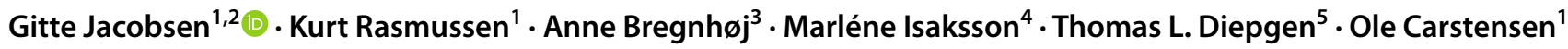

Received: 30 October 2020 / Accepted: 11 July 2021 / Published online: 19 October 2021

(c) The Author(s) 2021

\begin{abstract}
Purpose Irritant contact dermatitis (ICD) is a major cause of occupational disease. The aim was to review the relation between exposure to occupational irritants and ICD and the prognosis of ICD.

Methods Through a systematic search, 1516 titles were identified, and 48 studies were included in the systematic review. Results We found that the evidence for an association between ICD and occupational irritants was strong for wet work, moderate for detergents and non-alcoholic disinfectants, and strong for a combination. The highest quality studies provided limited evidence for an association with use of occlusive gloves without other exposures and moderate evidence with simultaneous exposure to other wet work irritants. The evidence for an association between minor ICD and exposure to metalworking fluids was moderate. Regarding mechanical exposures, the literature was scarce and the evidence limited. We found that the prognosis for complete healing of ICD is poor, but improves after decrease of exposure through change of occupation or work tasks. There was no substantial evidence for an influence of gender, age, or household exposures. Inclusion of atopic dermatitis in the analysis did not alter the risk of ICD. Studies were at risk of bias, mainly due to selection and misclassification of exposure and outcome. This may have attenuated the results.

Conclusion This review reports strong evidence for an association between ICD and a combination of exposure to wet work and non-alcoholic disinfectants, moderate for metalworking fluids, limited for mechanical and glove exposure, and a strong evidence for a poor prognosis of ICD.
\end{abstract}

Keywords Occupational contact dermatitis · Irritant contact dermatitis $\cdot$ Hand eczema $\cdot$ Skin exposure $\cdot$ Prognosis

Thomas L. Diepgen passed away march 2020.

Gitte Jacobsen

gitte.hojbjerg.jacobsen@rsyd.dk

1 Department of Occupational Medicine, Danish Ramazzini Centre, Regional Hospital West Jutland, University Research Clinic, Herning, Denmark

2 Department of Occupational Medicine, Hospital South West Jutland, University Hospital of Southern Denmark, Esbjerg, Denmark

3 Department of Dermatology, Aarhus University Hospital, Aarhus, Denmark

4 Department of Occupational and Environmental Dermatology, Skåne University Hospital, Lund University, Malmö, Sweden

5 Department of Clinical Social Medicine, Occupational and Environmental Medicine, University Hospital Heidelberg, Heidelberg, Germany

\section{Introduction}

Irritant contact dermatitis (ICD) is a common disease. General population studies have reported incidences of non-specific hand eczema (HE) of around 5.5/1000 person-years, point prevalence around 4\%, 1 year prevalence around 10\%, and a lifetime prevalence of $15 \%$, with ICD being the most prevalent type and the highest frequency of self-reported HE being among young women (Thyssen et al. 2010). Contact dermatitis (CD), mainly HE, is the most frequently recognized industrial injury in Denmark with up to 2000 annual cases recognized and compensated by the Danish National Board of Industrial Injuries (AES 2016). Allergic cases constitute $30 \%$ of the recognized cases of occupational contact dermatitis (OCD), while around $70 \%$ are caused by irritant exposures, mainly wet work, but also to use of occlusive gloves, exposure to fresh food, detergents, various oils, and dirt. The majority, around 70\%, of the recognized cases of 
occupational ICD (OICD) in Denmark are in females (Caroe et al. 2014).

The majority of studies with clinical estimations of the incidence of occupational skin diseases (OSD) are based on occupational disease registers in which the reported incidences of OCD may vary from 5 to 19 cases per 10,000 fulltime worker years (Diepgen 2003; Diepgen and Coenraads 1999; Keegel et al. 2009; Lushniak 2003). These national registers are usually incomplete due to underreporting of the diseases, and registers are often not fully comparable because of differences in reporting practices across countries. In Denmark, underreporting of OCD among hairdressers was estimated in a register-based questionnaire study that found that only $21 \%$ of hairdressers with HE were reported to the National Board of Industrial Injuries (Lysdal et al. 2012). In the United Kingdom, data on OCD cases showed that occupational physicians reported substantially more cases than dermatologists, with overall incidences of OCD per 10,000 worker being reported by 5.1 and 0.7 (from 1996 to 2001) (McDonald et al. 2006) and 2.6 and 0.7 (from 2002 to 2005) (Turner et al. 2007).

The Saarland study from Germany reported an overall annual incidence of OSD of 6.8 per 10,000 workers in 16 occupational groups, based on 263 notifications of confirmed OSD, where $75 \%$ involved ICD. The annual incidences of OSD ranged from 1.5 to 48 per 10,000 highest among hairdressers, followed by bakers/pastry cooks, cooks, and nurses (Dickel et al. 2002a). Similar results were reported in a study from Northern Bavaria of 3,097 patients with OSD from 24 occupational groups; ICD was seen in 57\%, and in combination allergic contact dermatis (ACD) in 15\%. The annual incidence of ICD was 4.5 per 10,000 workers (Dickel et al. 2002b).

A Danish survey based on 758 recognized notified cases also found the highest overall annual incidence rates of OICD at 51.7 and 46.6 per 10,000 workers among highexposed bakers and hairdressers (Skoet et al. 2004).

Currently, there is a general lack of knowledge, and no systematic reviews regarding the exposures sufficient to cause irritant eczema or aggravate pre-existing eczema. Previously only few systematic reviews on OICD have been published, mainly focusing on treatment and prevention (Bauer et al. 2018; Nicholson et al. 2010). Until recently, only a few epidemiological studies of OICD have been published, and most of our knowledge about OICD has been derived from clinical case reports and clinical studies of groups of patients with little differences in exposure(Diepgen and Coenraads 1999).

Our aim was to perform a systematic review to present:

- An assessment of the risk of ICD in relation to the character, level, severity, and duration of the exposure (doseresponse relation) to occupational irritants,
- A description of the time of onset of the disease in relation to exposure and possible threshold values (lower limit of effect).

- And an assessment of the prognosis of ICD as well as the impact of continuous exposure on prognosis and the effect of cessation of exposure.

\section{Background}

\section{The outcome: definition of ICD and irritant HE}

CD has been defined by the European Society of Contact Dermatitis (ESCD) as an eczematous local inflammatory skin reaction caused by direct and usually repeated exposures, to harmful objects or chemicals, which, depending on location of contact, can occur anywhere on the body. CD is clinically characterized by redness of the skin, itching papules, or vesicles, but may vary from slight hyperkeratosis to fissures, swelling, scaling, and oozing. Histopathological CD is characterized by inflammation in the superficial parts of the skin, i.e., the outermost layers of the dermis with involvement of the epidermis. Healing is without scars. Besides ICD, there are three other forms of $\mathrm{CD}$, with the most important being ACD, which is characterized by an acquired hypersensitivity with involvement of "allergen-specific" $T$ cells as mediators of the inflammatory skin reaction. Another type of $\mathrm{CD}$ is photocontact dermatitis, which is the result of an interaction between a harmful substance in the skin and ultraviolet radiation. This can be either photoallergic contact dermatitis, which is an immunological disease much like contact allergy but where UV is required, or a phototoxic dermatitis, a non-allergic reaction that can happen to anyone exposed to the chemical in question and UV radiation. Finally, CD may be a type 1 allergic reaction, contact urticaria based on IgE specific antibodies, and protein contact dermatitis (ESCD 2020; Rustemeyer et al. 2011).

ICD is the most common variant of $C D$, and ICD has traditionally been defined as a local inflammatory non-specific reaction of the skin without requiring prior sensitization of the immune system, following single or repeated exposures to an irritant, which can be defined as any agent, psychical or chemical, capable of producing cellular perturbation if applied for sufficient time and in sufficient concentration (Ale and Maibach 2014).

ICD is not a clinical entity, but rather a spectrum of diseases, with different clinical presentations and etiological factors. Clinical entities have been described by some authors to encompass a classification scheme of 10 main phenotypes based on both morphology and mode of onset, with the following seven most relevant in an occupational setting: 
(1) Acute ICD, (2) delayed acute ICD, (3) irritant reactions, (4) cumulative (chronic) ICD, (5) traumatic ICD, (6) acneiform ICD, and (7) friction ICD (Ale and Maibach 2014).

Irritant HE is the major location of ICD, and as for CD and ICD in general, no gold standard for HE diagnosis or classification of HE exists (Agner et al. 2015).

A classification of $\mathrm{HE}$ recommended in guidelines (Diepgen et al. 2015) from the ESCD is based on a combination of etiology and morphological signs, with the following subgroups of HE: ICD, ACD, atopic HE, contact urticaria (CU)/protein $\mathrm{CD}$, vesicular/pompholyx endogenous HE, and hyperkeratotic and endogenous HE, with further combination of diagnoses, e.g., ICD with and without atopic HE and combined ICD and ACD. The subgroup of ICD requires a documented exposure of the hands to an irritant being quantitatively likely to cause $\mathrm{CD}$, with no relevant contact allergy, while $\mathrm{ACD}$ and allergic $\mathrm{CU}$ require relevant exposures to contact allergens identified by patch or prick tests (Agner et al. 2015; Diepgen et al. 2009; Diepgen et al. 2015).

No specific diagnostic test exists for ICD, and a diagnosis is made clinically as an exclusion diagnosis based on no findings of allergic $\mathrm{CD}$ and a temporal relationship to a history of supposed relevant irritant exposures (Friis et al. 2014).

\section{The exposures}

Occupational ICD has been described in relation to exposure to various chemicals, soluble oils/metalworking fluids (MWF), wet work, detergents, occlusion by gloves, foods, exposure to plants, and mechanical friction.

The most prevalent exposures are wet work in various industries, including healthcare, cleaning, hairdressing, or exposure to chemical substances, e.g., MWF.

The criteria and definition of wet work, are not well defined internationally. The German Approved Code practice TRGS 401 (technical rules of hazardous substances) in 1996 defined criteria for wet work as regular work $>2 \mathrm{~h} /$ day, with the hands exposed to a wet work environment or regular use of occlusive gloves for the same period or frequent or intensive handwashing (BAuA 2008). A definition of frequent or intensive handwashing is not given in the TRGS, but has been suggested in the literature to about 20 times/ day (Diepgen and Coenraads 1999).

Non-occupational exposures to irritants in the home environment including hobby activities may be of relevance in both research and clinical cases. Examples are domestic activities like dishwashing, cleaning, and childcare, but also hobby activities like mechanical repair, construction work, and use of different types of glue, etc. (Ibler et al. 2012; Meding et al. 2013; Thyssen et al. 2010; Visser et al. 2014a).

\section{Atopy and other genetic factors}

Atopic disposition, especially a personal history of childhood atopic dermatitis (AD), has been described as a wellknown risk factor for increased susceptibility for irritant HE/ ICD (Diepgen and Coenraads 1995). A history of AD has been reported to increase the odds ratio (OR) of developing HE by a factor 3 in both wet and dry work (Coenraads and Diepgen 1998; Nilsson et al. 1985).

Other relevant factors include variations/polymorphisms of genes involved in the skin barrier function and inflammatory mediators including cytokines and polymorphism of gene coding for the epidermal protein filaggrin, which, as a structural protein in the epidermis, is important for the formation of the epidermal skin barrier (Davis et al. 2010; de Jongh et al. 2008; Diepgen et al. 2015; Kezic et al. 2009; Landeck et al. 2012; Visser et al. 2013; Visser et al. 2014a).

\section{Previous hand eczema}

Previous episodes and early onset of $\mathrm{HE}$ are also well-known risk factors for the development of HE, including ICD. This probably relates to individuals with increased susceptibility due to inborn characteristic of the skin, including atopic skin disease, but possibly also due to behavioral patterns regarding habits of skin protection and handwashing (Diepgen et al. 2015; Mortz et al. 2014).

\section{Gender, age, and smoking}

ICD including OICD is almost consistently reported to be more frequent in women, especially young women. However, no gender difference regarding irritant reactivity has been confirmed in experimental studies, and as many female-dominated occupations, e.g., HCW, cleaners, and hairdressers involve more extensive wet work along with females spending more time with wet work at home, the difference between male and females is suspected to be due to differences in occupational and non-occupational exposure to irritants (Anveden Berglind et al. 2009; Meding 2000; Meding et al. 2016; Thyssen et al. 2010).

Skin susceptibility to irritation decreases with increasing age. Population studies on hand eczema have consistently shown a trend toward declining frequency with age, especially among women (Slodownik et al. 2008; Thyssen et al. 2010).

The relation between smoking and HE has recently been evaluated in a review including 20 epidemiological studies with conflicting and inconsistent results. Approximately half the studies showed an increased prevalence and/or severity of HE in smokers, while the other half reported no association, although a protective effect of smoking was only reported in one study (Sorensen et al. 2015). 


\section{Methods}

\section{Literature search}

The systematic review is based on PRISMA (Preferred Reporting Items for Systematic Reviews and Meta-Analyses) (Moher et al. 2009), a revision of the QUOROM statement (quality of reporting metanalysis) (Moher et al. 1999). The literature search was initially performed in the following international databases: PubMed, Embase, Web of Science, and OSH-update (HSELINE, NIOSHTIC, CISDOC, and RILOSH) in November 2015. The search was later updated in PupMed until 3 March 2020. The literature search was broad and included combinations of Mesh or text search terms for outcome (contact dermatis, hand dermatoses, dermatitis, and occupational dermatitis), irritative skin exposure (irritants, phototoxic, wet work, detergent, cutting fluid, and industrial oils), and work relation (occupational exposure, occupational diseases, occupation, and industry). Details on the search strategy for the different databases are presented in table S1 of the Online Supplementary Material.

We included papers with abstracts published in English, Danish, and German from January 1980 to March 2020. The first author performed the initial title screening based on the title of the articles.

In further screening of abstracts and articles, each paper was reviewed independently by two members of the group. The two reviewers had to agree on the inclusion criteria of each paper before enrollment for dataextraction.

\section{Inclusion criteria}

Preselection of articles on associations between irritant exposures and ICD was based on the following eligibility criteria:

1. Original epidemiologic peer-reviewed studies on occupational exposure to irritants and outcome of ICD.

2. Study design included case-control, cross-sectional, and follow-up studies. Case studies, case series (patient populations reporting on proportion of ICD and ACD), meta-analyses, and reviews were excluded.

3. The included studies had to provide qualitative or quantitative exposure contrast either within the exposed group or include a control group without exposure.

4. Regarding outcome of ICD, we included studies which reported ICD or irritant changes resembling mild cases. We included studies with clinical assessment including patch test, but also studies with less diagnostic accuracy, i.e., studies with clinical examinations but no patch tests.
Studies based on self-reported outcome of HE were also included if the studied association was presumed to be to irritant work exposures.

5. Studies with main focus on $\mathrm{AD}, \mathrm{ACD}$, and $\mathrm{CU}$, without indication of ICD or exposure to irritants, were excluded.

6. Regarding studies on prognostic factors of ICD, we only included follow-up studies of cohorts with clinically verified occupational ICD. Studies with sole focus on treatment or prevention, e.g., use of barrier creams, were excluded.

\section{Data assessment: data extraction, quality, bias, and confounding}

From each study, we extracted core information relevant for a description of relations between occupational exposures and diagnosis or symptoms of ICD and also on individual risk factors and prognosis of ICD, assessment of internal validity, and the overall quality of the studies (Table S2 in Online Supplementary). Two reviewers independently extracted the information, and disagreements were resolved by discussion.

We systematically assessed all studies to grade for eight quality dimensions resembling risk of bias and confounding (Beer et al. 2015). Quality factors were related to: study design (3 parameters), exposure assessment (2 parameters), outcome ( 2 parameters), and confounding (1 parameter).

Quality factors were dichotomized in each study by a score of 0 (low quality/high risk) or 1 (high quality/low risk) according to the following criteria:

i. Study design: cohort study or case-control study with population or hospital control vs case-control studies with convenience controls and cross-sectional studies

ii. Size of study, number of participants: $>75$ cases vs $<75$ cases

iii. Response rate $>60 \%$ vs $<60 \%$ (in cohort studies defined as proportion of baseline participating at follow-up)

iv. Source of exposure information: non-self-reports vs self- reports

v. Exposure measure: quantitative or semi-quantitative vs qualitative

vi. Source of diagnosis: hospital vs surveillance schemes, questionnaire, or not well-defined sources

vii. Diagnosis: well-defined diagnostic criteria for ICD vs other criteria

viii. Possible confounding: age, gender, atopy in adjusted analyses or by matching being taken into account vs age, gender, and atopy not being taken into account. 
Based on the above quality factors and a discussion on the overall quality of the paper, each study was assigned a grade from 1 to 5 , corresponding to highest, high, medium, low, and un-acceptable quality (Table S3 of the Online Supplementary).

When the study did not provide any kind of risk estimate, we calculated prevalence ratios, relative risk, or the OR based on the available data - whenever feasible calculations has been marked with asterisks $\left(^{*}\right)$ in the text and tables.

We rated the overall level of evidence of a causal association between a given exposure and a specific outcome according to a classification system established by The Scientific Committee of the Danish Society of Occupational and Environmental Medicine, and adopted by the Danish Working Environment Research Fund (details in S4 of the Online Supplementary Material).

The following categories were used:

+++ strong evidence of a causal association

++ moderate evidence of a causal association

+limited evidence of a causal association

0 insufficient evidence of a causal association or evidence suggesting lack of a causal association -evidence suggesting lack of causal association.

For studies publishing multiple articles on the same issue, we included each paper if it provided additional information of the relation between exposure and OICD.

\section{Results}

\section{Selection of papers}

The literature search, after removal of duplicates, resulted in a total of 1514 articles. In all, 1000 papers originated from PubMed, 218 from Embase, 189 from OSH-update, and 107 from Web of Science. Based on the title, 943 articles were excluded, and 38 articles without an abstract were excluded. The remaining 533 articles were evaluated based on the abstract, which resulted in exclusion of 335 articles. 198 articles were evaluated by reading of full text and 145 articles did not meet inclusion criteria. In addition, two snowball articles were included based on references in included articles and reviews, resulting in 55 epidemiological papers from 48 studies (Fig. 1). The large number
Fig. 1 Flowchart of the inclusion of studies

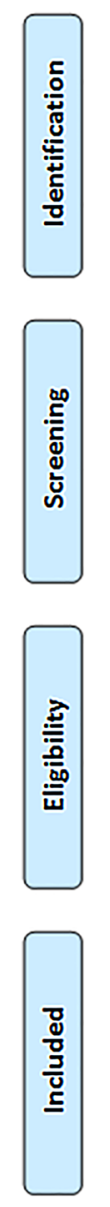


of articles excluded by title and abstract were due to the broad literature search, which resulted in numerous articles with titles related to non-relevant outcome and exposures, e.g., ACD due to specific allergies and abstracts for studies clearly not meeting inclusion e.g., case series of patient populations.

Diagnostic outcome based on a clinical diagnosis with patch testing that made it possible to distinguish ICD from ACD was measured in 11 studies (Table 1). Eleven studies relied on clinical diagnosis without patch test (Table 2) and 16 studies relied on self-reported outcome (Table 3 ). Altogether 11 studies involved prognosis of ICD (Table 4).

Table S3 in the online supplementary material presents summary of the quality assessment of the selected papers.

\section{Wet work: exposure to water, disinfectants, and detergents/soaps}

\section{Design}

Exposure to disinfectants and soaps/detergents may itself cause irritation, although these exposures are often reported in combination with wet work and, therefore, the effect may be difficult to differentiate.

The main occupations recording wet work exposure in this review are studies conducted among healthcare workers (HCW), cleaners, hairdressers, and various industries like the food-related industry and manufacturing of rubber.

Exposure to wet work was reported in 21 epidemiological studies, 7 were follow-up studies, 12 cross-sectional studies, and 1 was a nested case-control study in specific occupations and industries (Tables 1, 2, 3). Furthermore, a population-based follow-up study of young adults from the general population was included.

\section{Exposure source and measure}

A study by Lan et al. (2011) among non-atopic nurses applied quantitative measurements of wet work exposure by observation, along with measurements of exposure to disinfectants and glove use. A follow-up study among apprentice nurses used diary cards to provide semi-quantitative measurements (Visser et al. 2014b).

The remaining studies relied on self-reported information on exposures in questionnaire and/or interviews.

Some of the studies included other exposure variables, such as fruit preparation and cleansing (Bauer et al. 1998), contact with specific detergents (Teo et al. 2009) and disinfectants (Flyvholm et al. 2007; Hamnerius et al. 2018; Held et al. 2001; Visser et al. 2014b), or industrial surfactant (Vermeulen et al. 2001). Studies of use of gloves, which may be a part of wet work, but will be treated separately in this review.

\section{Outcome}

Diagnosis of outcome was clinically assessed in nine studies (Apfelbacher et al. 2010; Bauer et al. 1998; Callahan et al. 2013; Guo et al. 1994; Held et al. 2001; Stingeni et al. 1995; Teo et al. 2009; Uter et al. 1999a; Vermeulen et al. 2001). Typical categories were mild or minor dermatitis, with irritant reactions described as slight erythema, chapping, and scaling, without morphology of papules, vesicles or fissures, and moderate and severe or major dermatitis.

In six of the studies without a clinically verified diagnosis, outcome relied on self-reported dermal symptoms resembling HE (Jung et al. 2014; Lan et al. 2011; Lee et al. 2013; Mirabelli et al. 2012; Nielsen 1996; Visser et al. 2014b), and in one study, the dermal symptoms affected other body parts than the upper extremities (Lazarov et al. 2005). In a study among nurses, the questionnaire was supplemented by a patch test in a sub-cohort (Lee et al. 2013). Five studies relied on self-reported HE (Hamnerius et al. (2018)) and four based on the same standardized questionnaire (Douwes et al. 2017; Flyvholm et al. 2007; Ibler et al. 2012; Mortz et al. 2014).

\section{Quality of the studies}

All the included studies could potentially be affected by bias or confounding. In the cross-sectional studies, exposure and outcome were collected simultaneously and a causal relation can only be suggestive. Selection bias due to healthy worker effect is likely in most studies and may attenuate the results of these studies, with a probable direction of bias toward unity. This is also the case if more susceptible individuals, i.e., individuals with atopic skin diathesis, are less likely to be exposed due to pre-work self-selection (Uter et al. 1999b).

As most of the studies relied on self-reported qualitative exposure assessment, it is also probable that exposure misclassification is present, leading to non-differential misclassification with dilution of exposure contrast, and possible attenuation of results.

In addition, studies may have been affected by a misclassification of outcome, particularly studies with questionnaire-based outcome. This is especially the case with studies with a symptom-based outcome in which there is a high prevalence of symptoms and low specificity, but if the outcome is non-differential, this will cause bias toward the null.

It is not possible to distinguish between ACD and ICD without including patch tests, and while wet work especially hand-washing can be regarded as a likely irritant, the lack of clinical assesment of possible ACD including patch testing for allergens is a major limitation in these studies. 


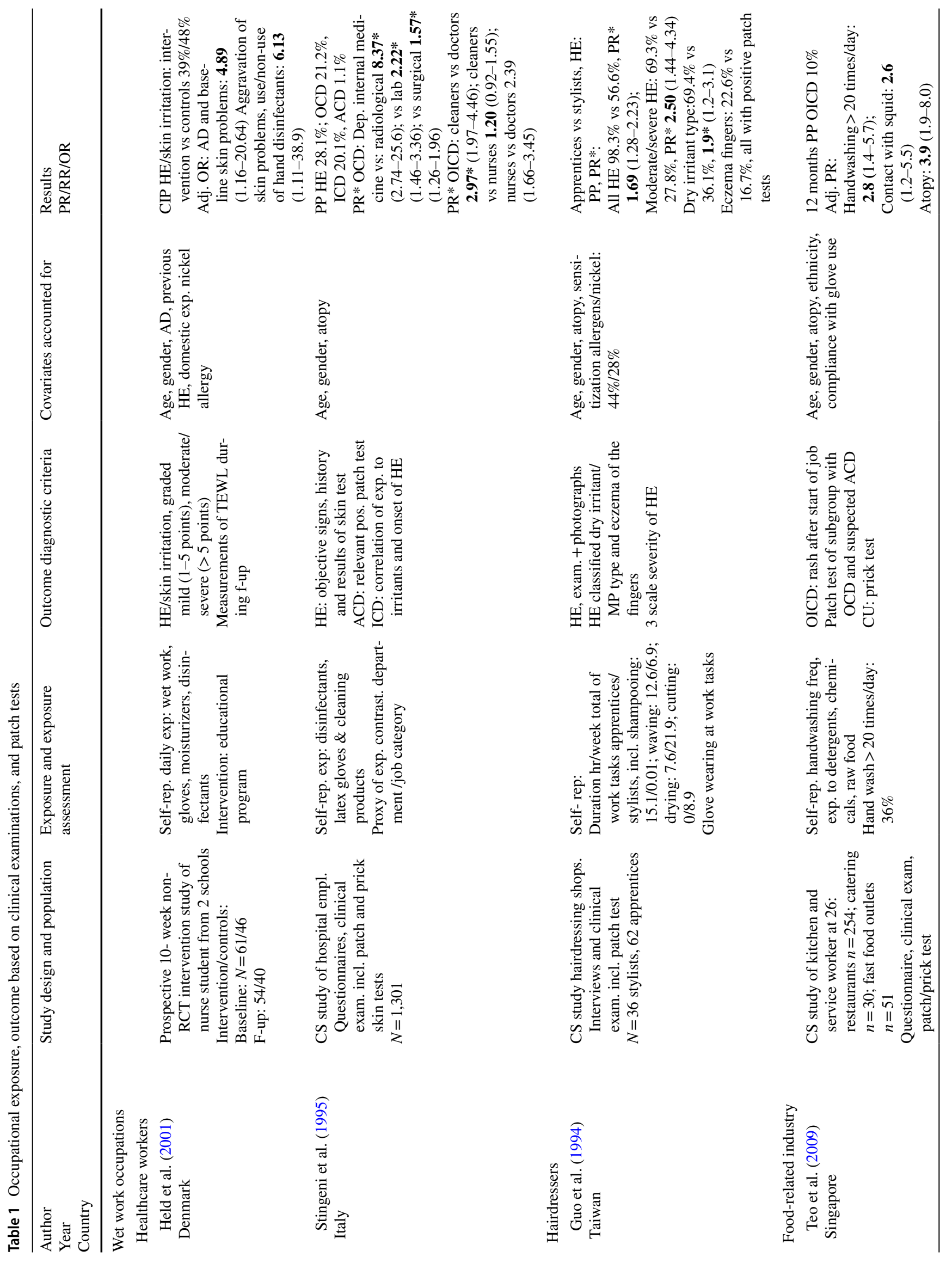




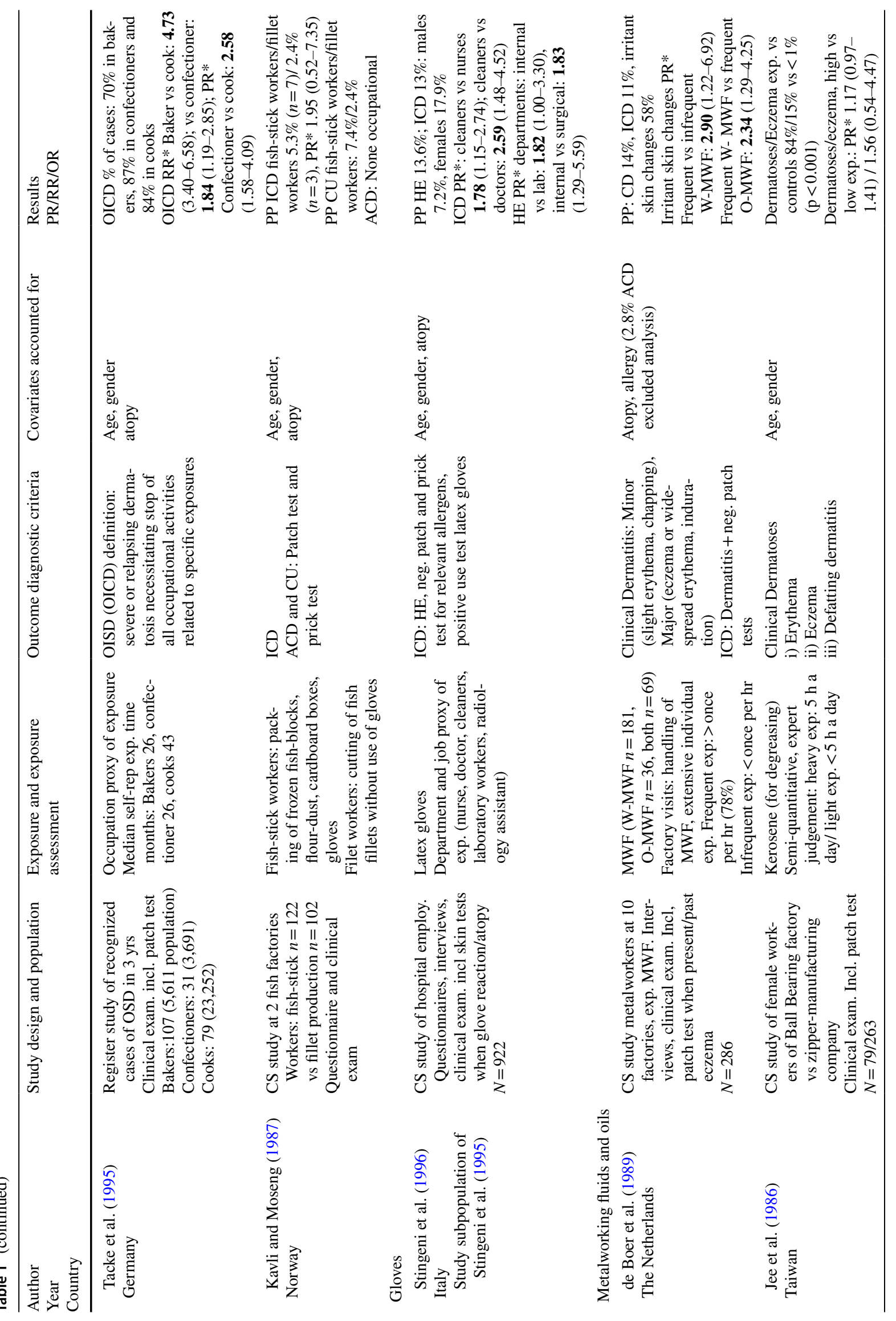




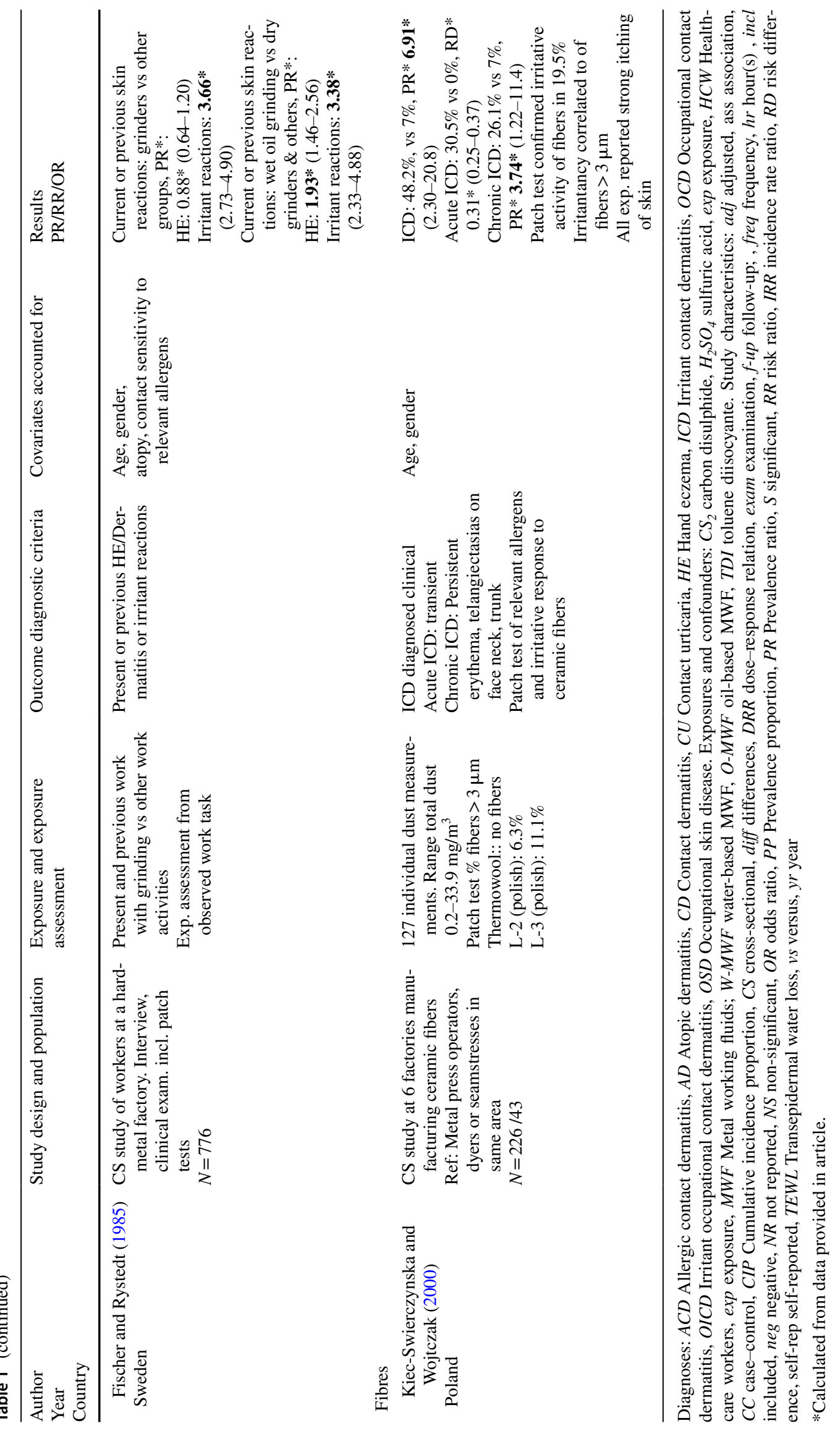




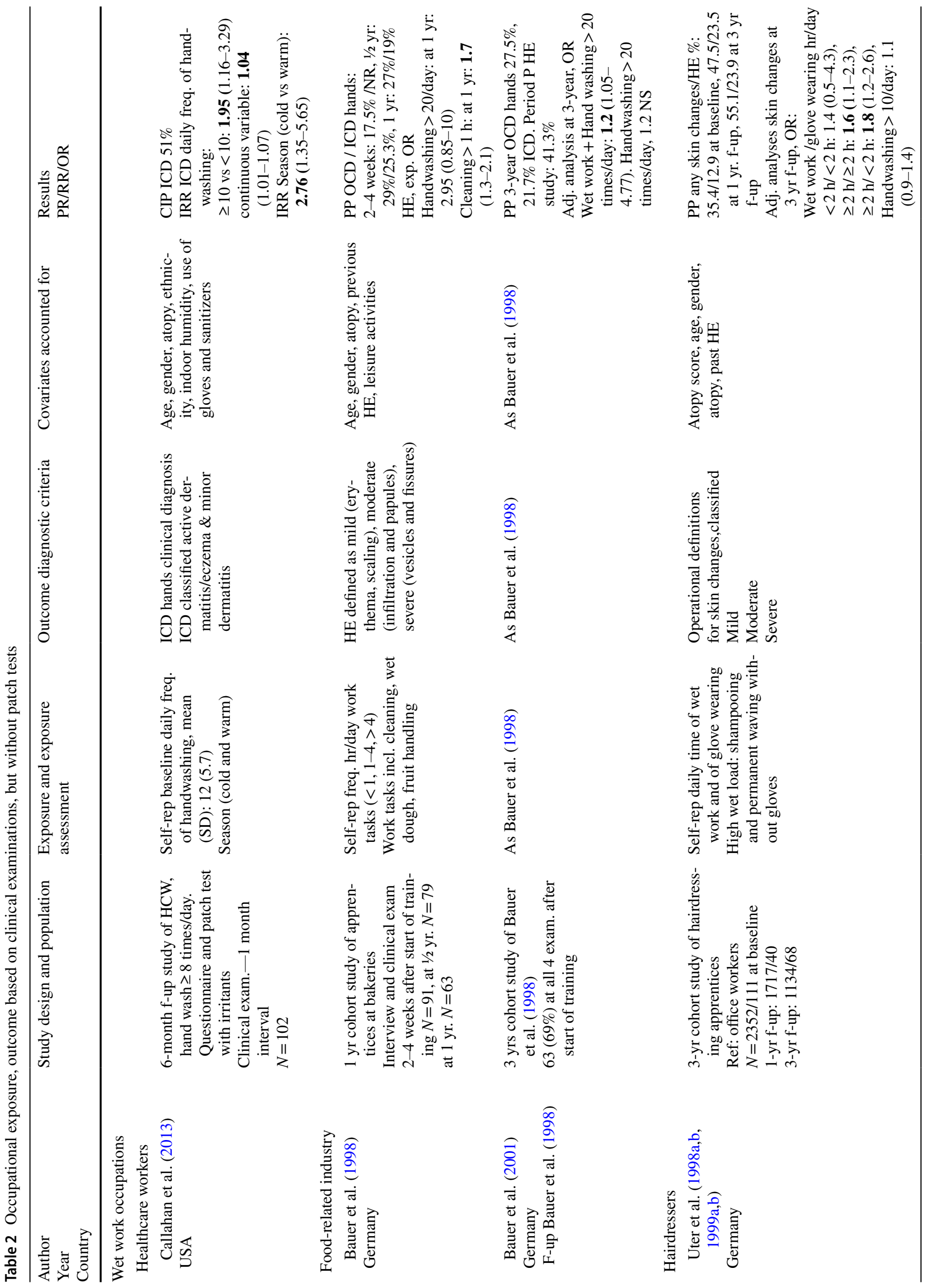




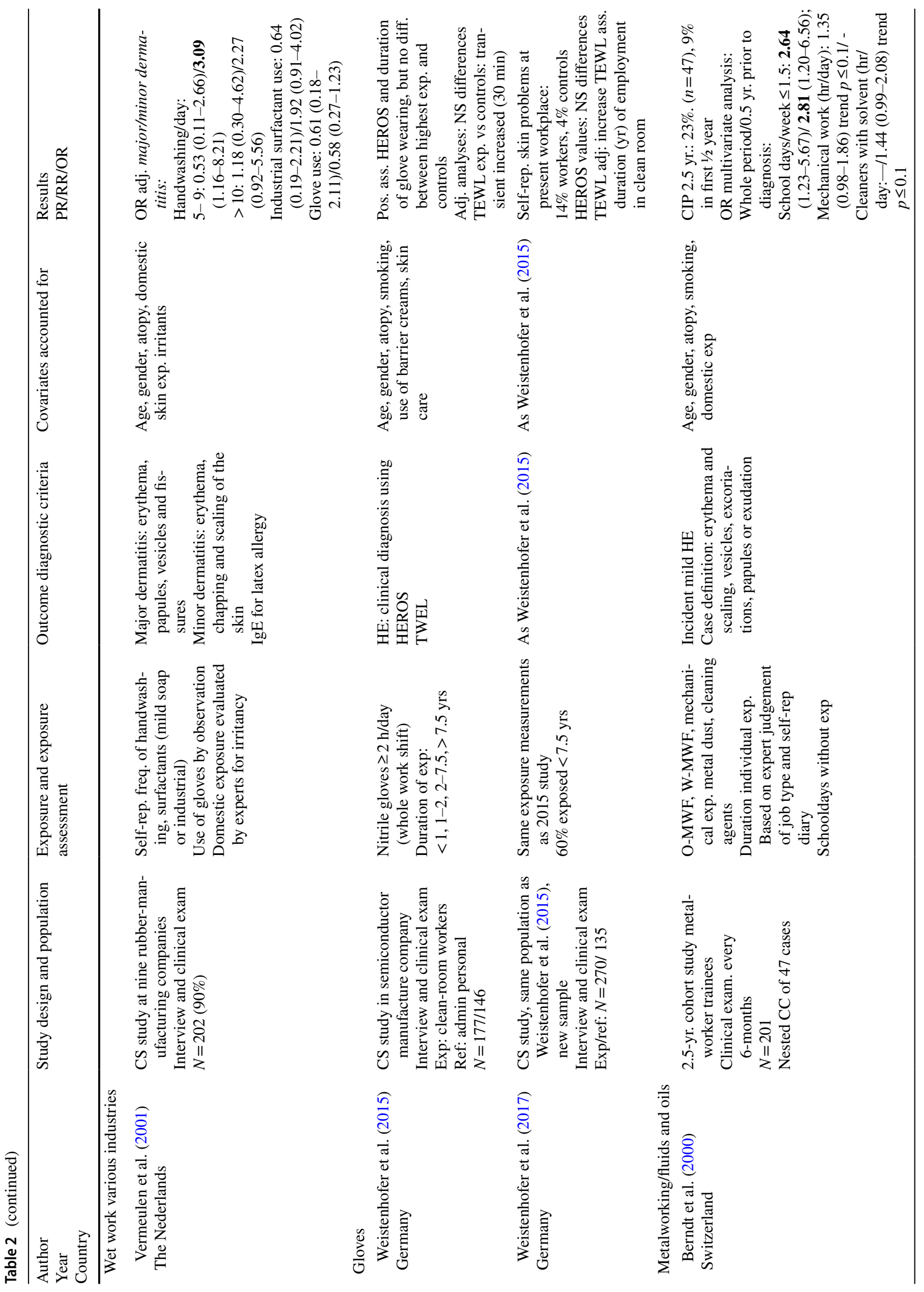




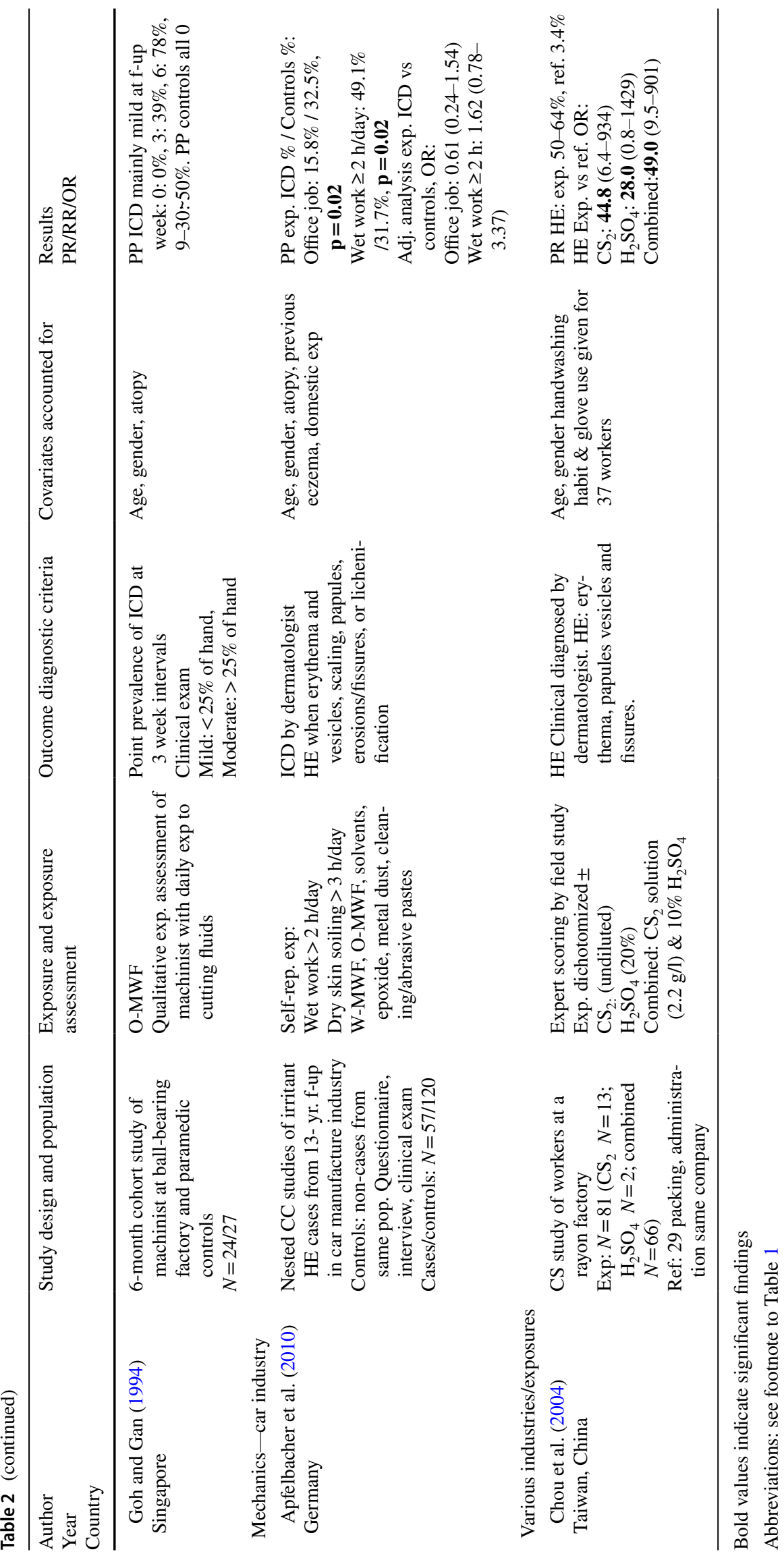




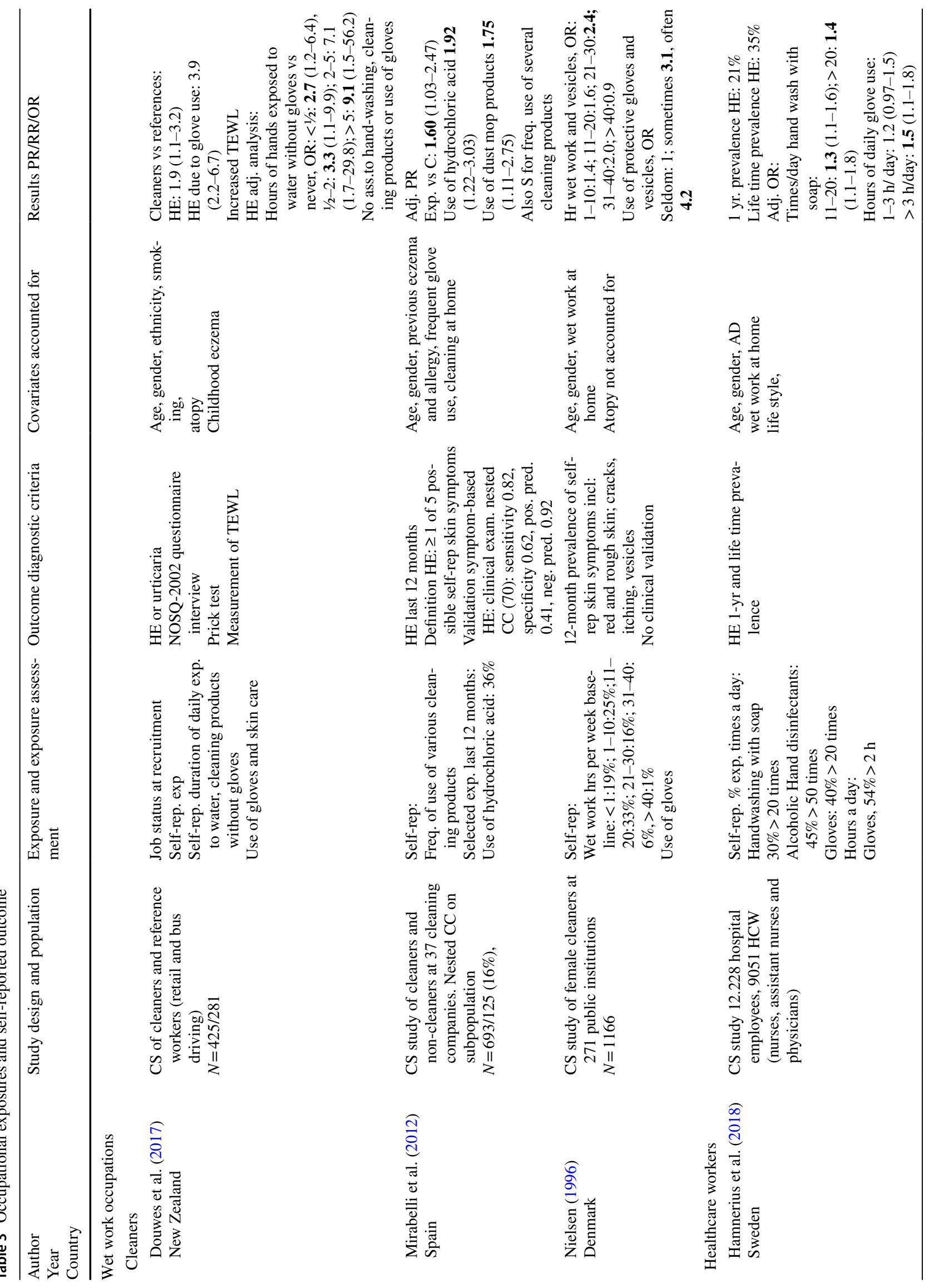




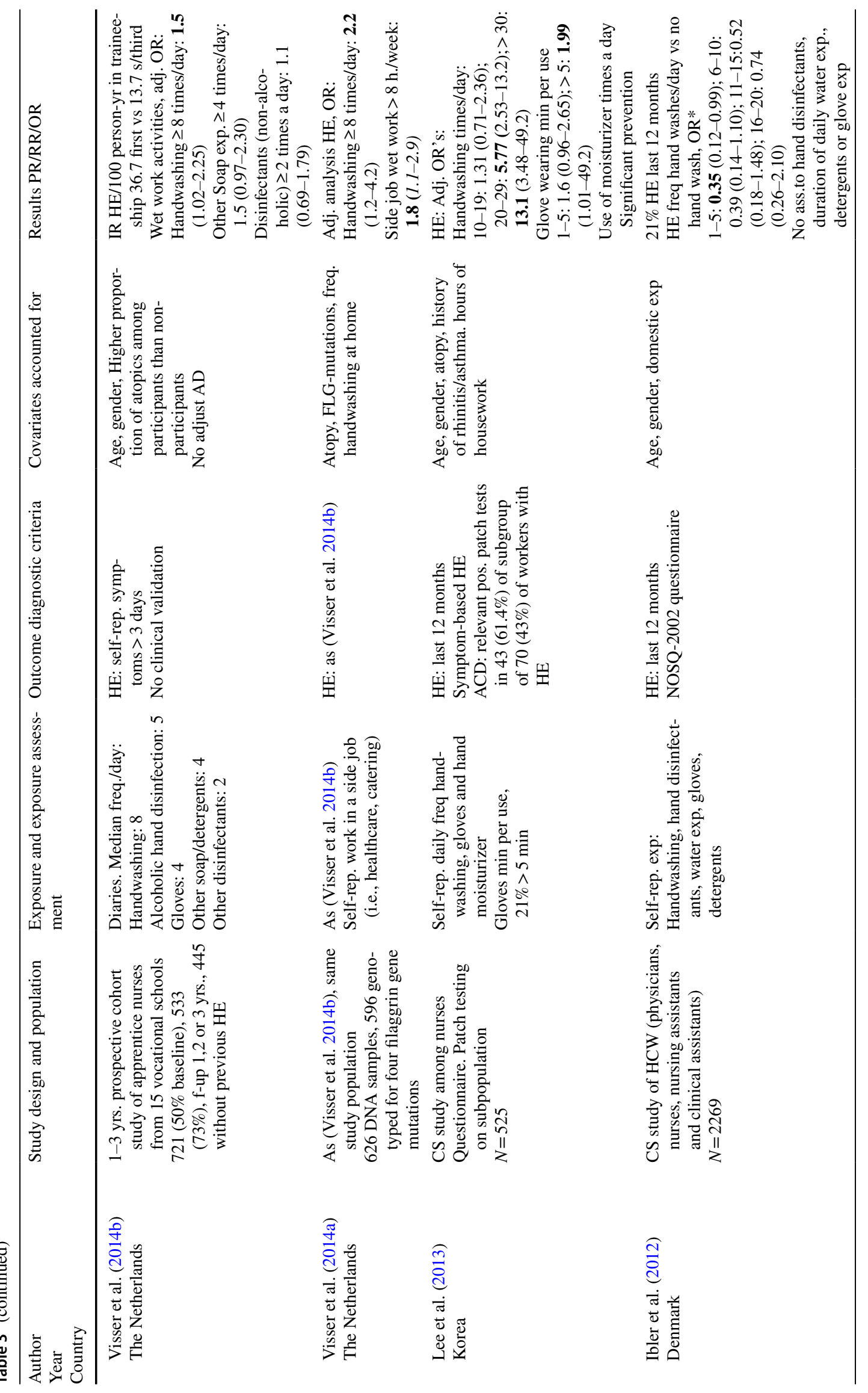




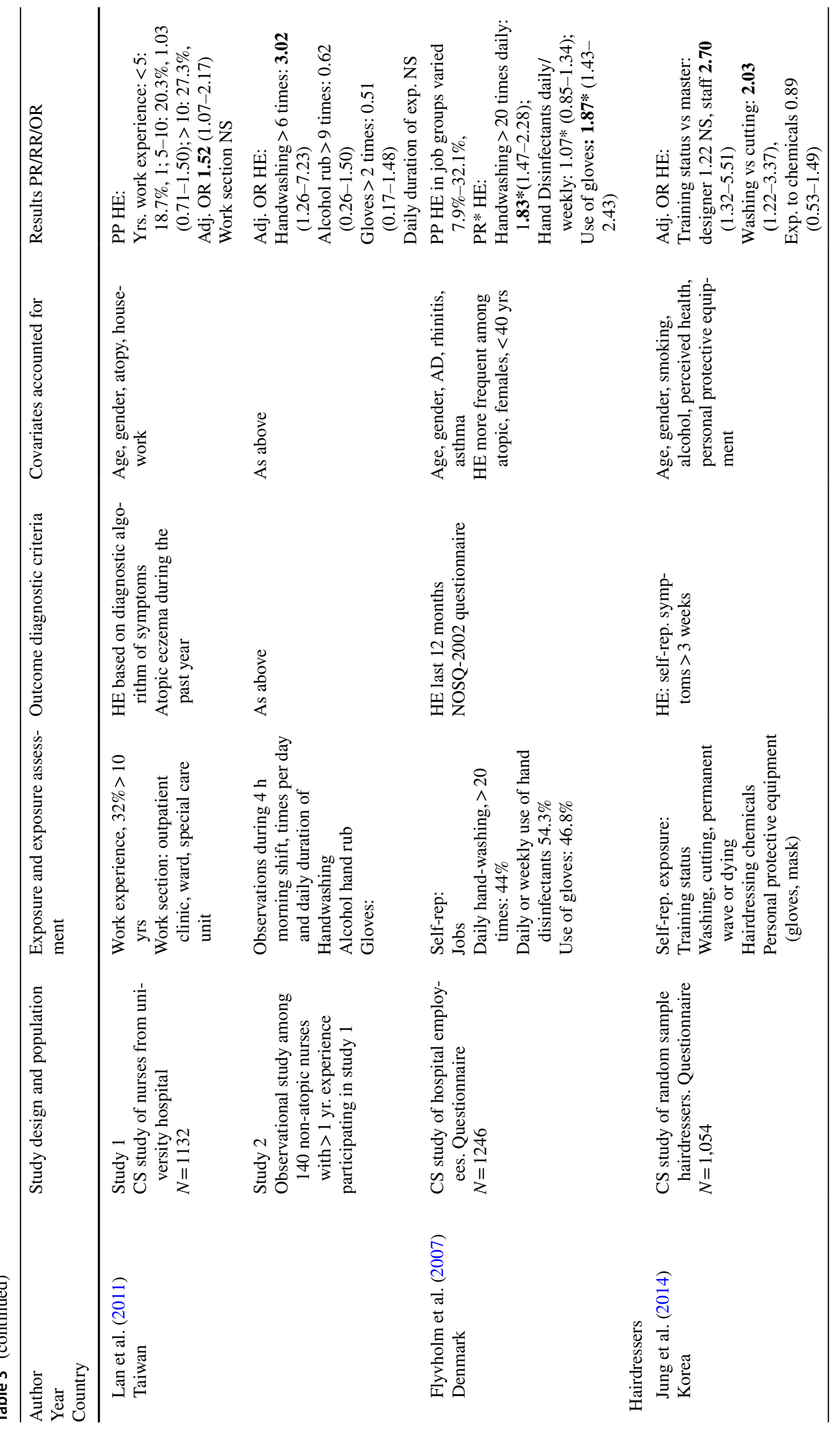




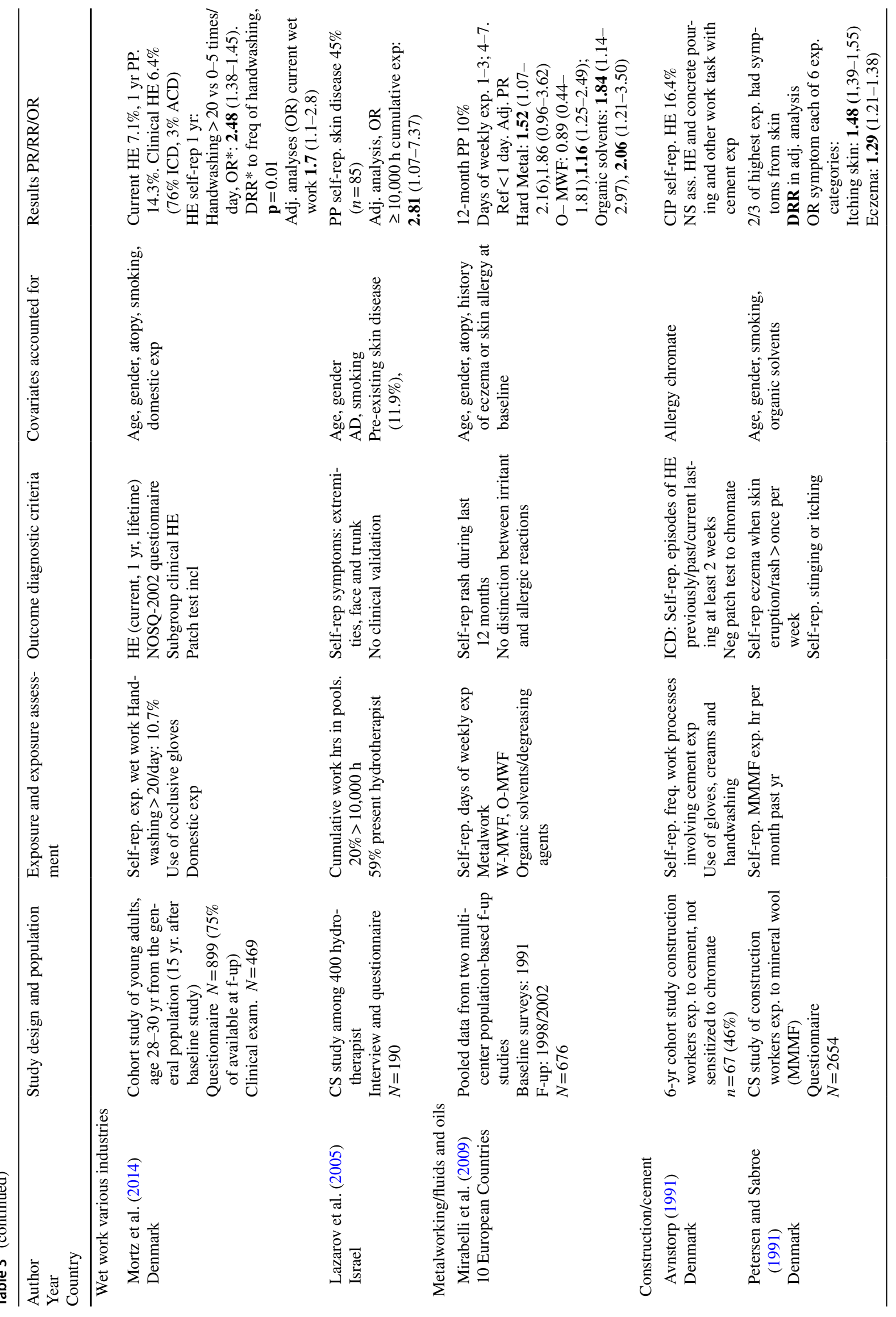




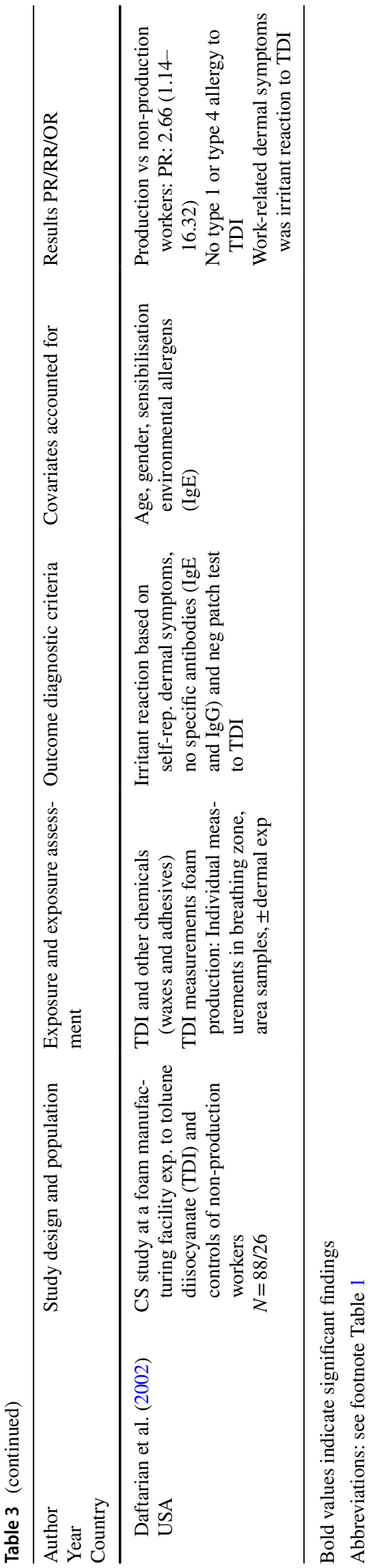

Taken together, all the studies had flaws of minor or major character, and no studies were regarded as being of the highest quality. Three studies were graded as high quality (Callahan et al. 2013; Lan et al. 2011; Uter et al. 1999a), 11 as medium quality, and the remaining 7 studies as low quality (for details, see online supplementary table S3).

\section{Results}

Overall, the studies across industries consistently pointed toward a moderate or low association between wet water exposure and probable ICD, especially regarding the frequency of exposure. We found no effect of alcoholic hand disinfection.

Callahan et al. (2013) in a 6-month follow-up study of $\mathrm{HCW}$ in the USA reported a dose-response relation to clinically verified $\mathrm{HE}$ for handwashing frequency as a continuous variable for both the adjusted point prevalence rate and the incidence rate ratio (IRR) of approximately 1.04 , and also to handwashing frequency $\geq 10$ times a day; point prevalence rate 1.55 (1.01-2.39), and IRR 1.95 (1.16-3.29) (Table 2).

Ibler et al. (2012) in a study on Danish HCW reported an increase of $\mathrm{HE}$ across five categories of handwashing until $>20$ hand washes.

Lee et al. (2013) in a study of Korean nurses reported a uniform increase in OR for self-reported HE across four handwashing categories, with a reference of $<10$ hand daily hand washes, significant for the categories 20-29 times/ day [OR 5.8 (2.5-13.2)] and for $>30$ times/day [OR 13.1 (3.5-49.2)] (Table 3).

Hamnerius et al. (2018) in a large cross-sectional study of about 9000 Swedish HCW reported a significant dose-response relation for HE for handwashing with soap, with OR 1.3 and 1.4 for $11-20$ and for $>20$ times/day, respectively (Table 3 ).

Among HCW, Visser et al. (2014b) in a follow-up study of apprentice nurses reported non-significant associations between $\mathrm{HE}$ and use of both soaps and non-alcholic disinfectants, but no associations with use of alcoholic hand rubs. Held et al. (2001) in a intervention study of apprentice nurses reported aggravation of skin problems associated with use of hand disinfectants (non-specific), OR 6, and Stingeni et al. (1995) in a study of hospital employees reported disinfectants, mainly chrohexidine gluconate and glutaraldehyde, and detergents/soaps, to be the main causes of OICD, while the frequency related to alcohol-based disinfectants was low. Other studies on HCW have reported no association between HE and use of alcoholic hand disinfectants (Hamnerius et al. 2018; Lan et al. 2011; Lee et al. 2013), or non-specified hand disinfectants/local disinfectans (Flyvholm et al. 2007; Ibler et al. 2012).

Vermeulen et al. (2001) in a study of rubber-manufacturing workers reported adjusted OR of minor dermatitis 


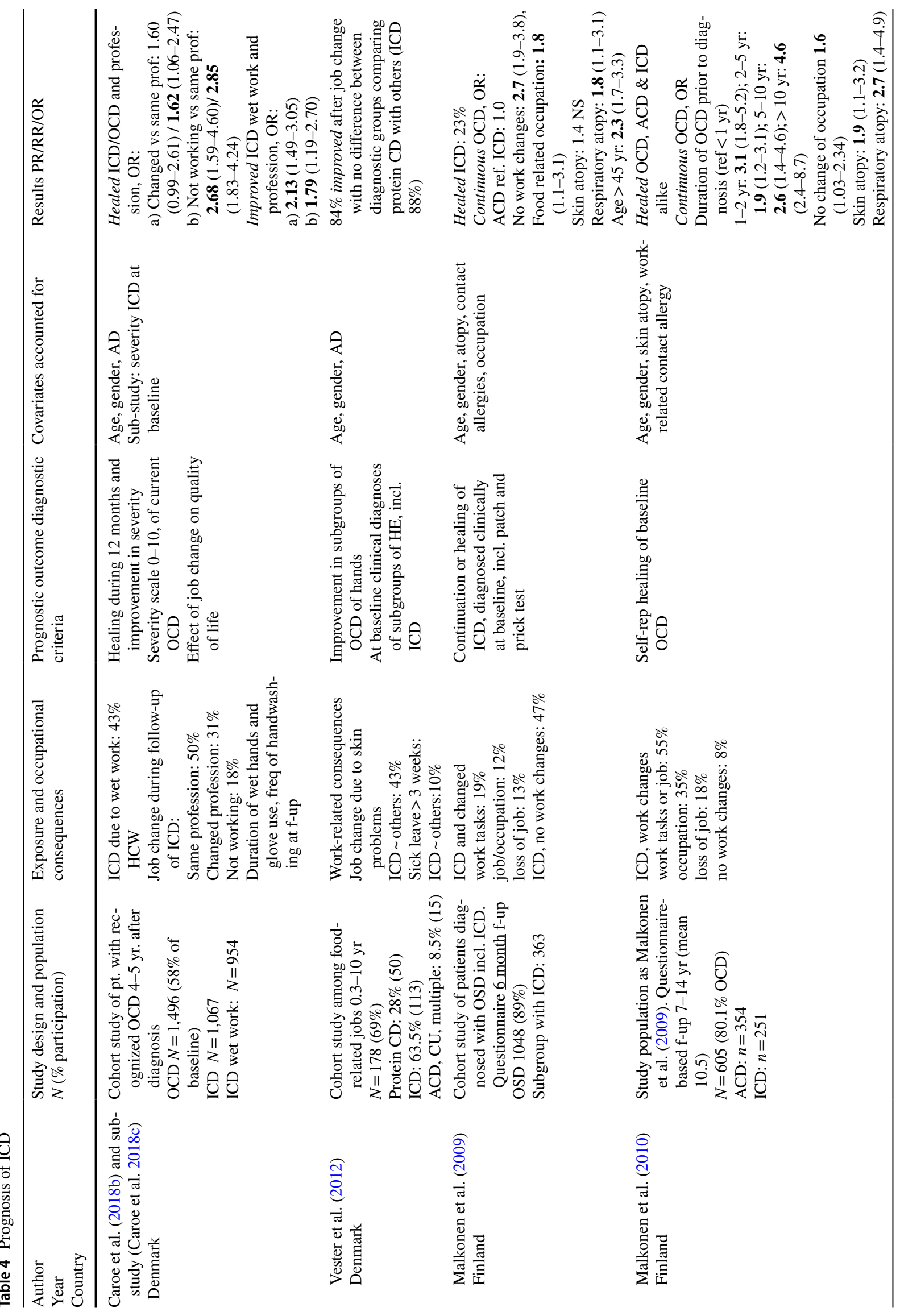




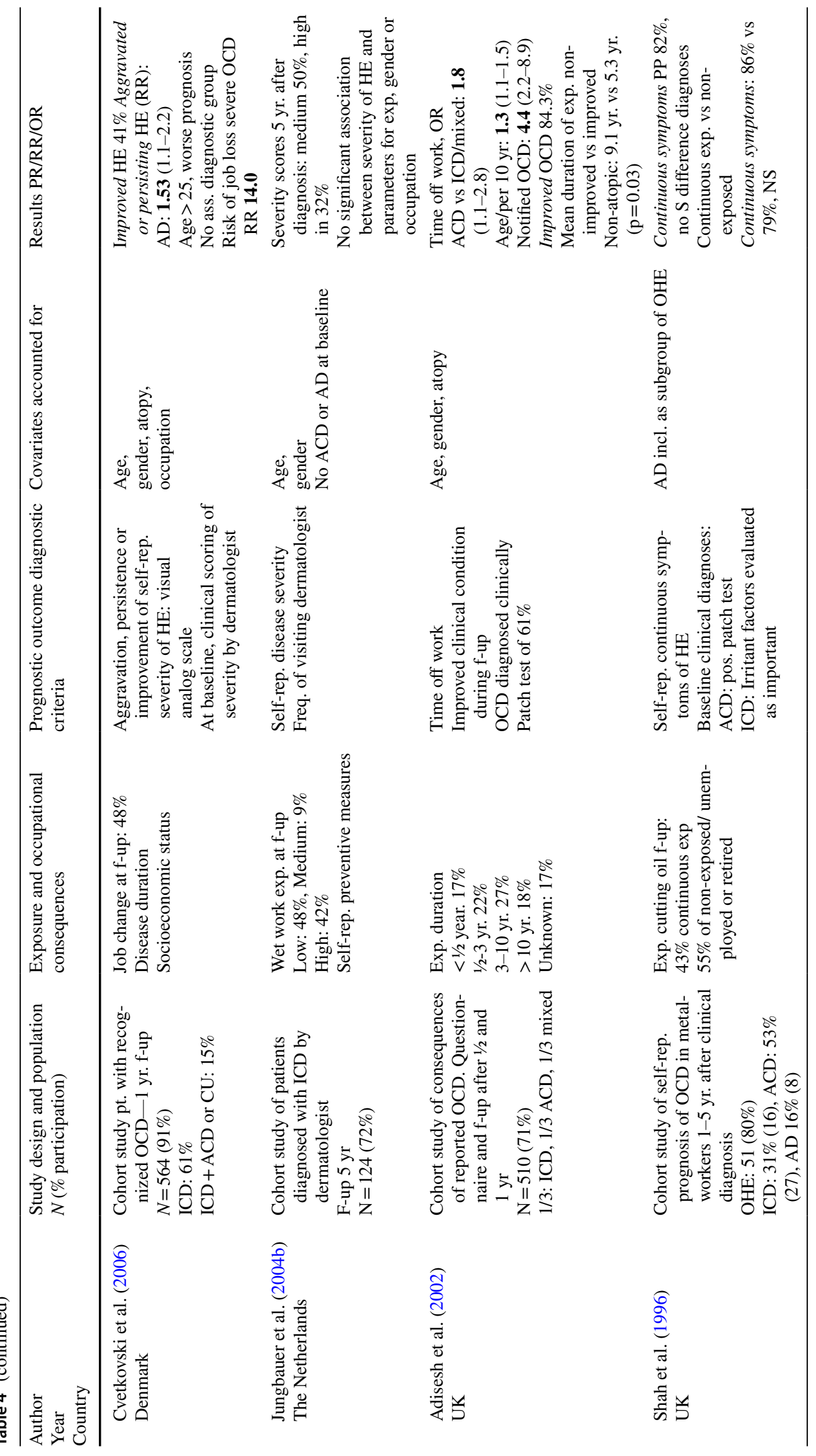




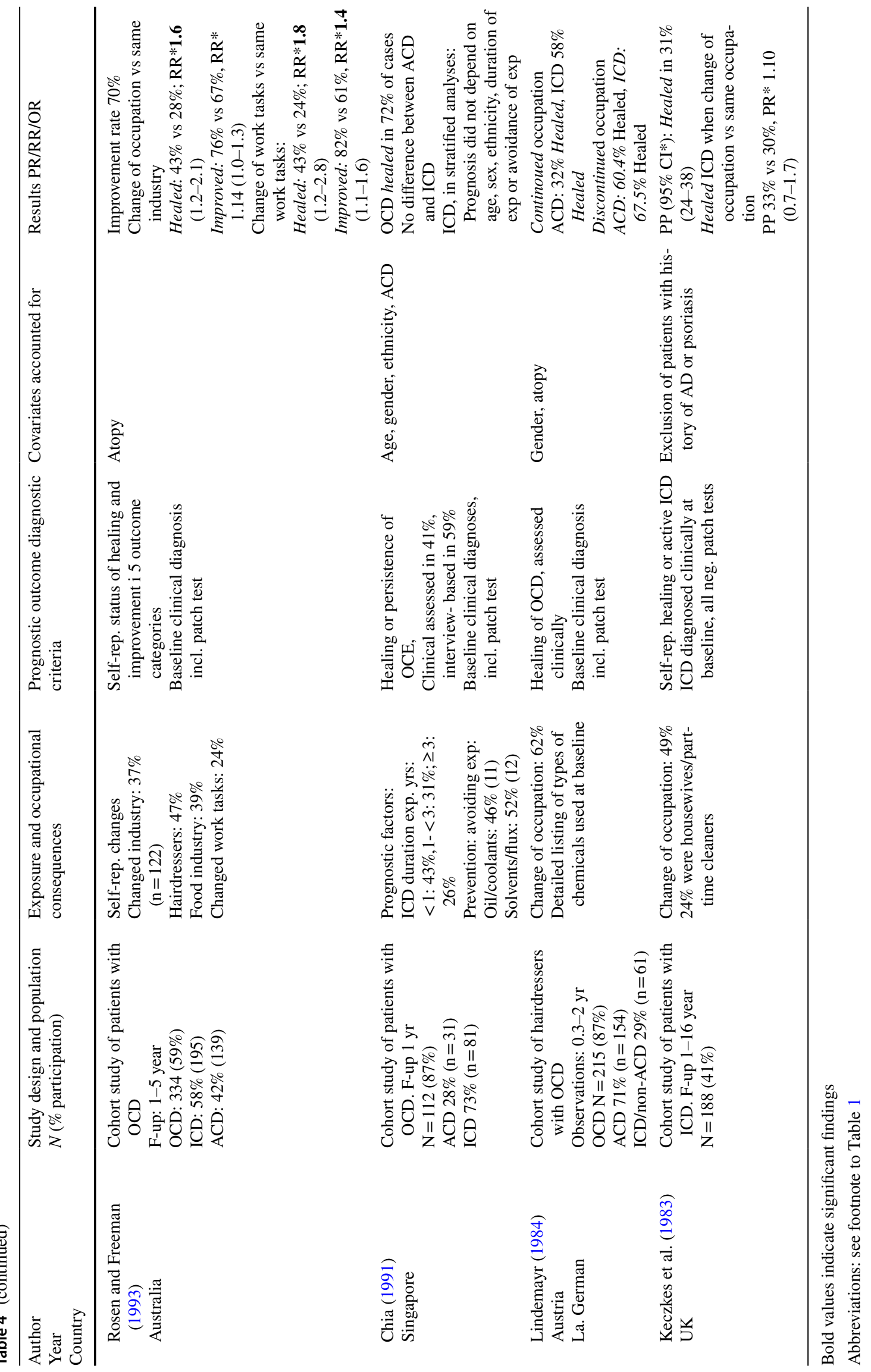


significantly increased for handwashing 5-10 times/day of 3.1 (1.2-8.7), but not for $>10$ times/day, although the latter also gave an OR above unity of $2.3(0.9-5.6)$. When combined with the use of industrial surfactant, but not regular hand soap, they found a dose-response relation with an OR of $4.3(0.9-20.3)$ and 6.4 (1.4-30.7) for handwashing 5-9 and $>10$ times per day, respective (Table 2).

Several cross-sectional studies have reported increased prevalence ratios or OR for dichotomized handwashing frequencies ranging from $>8$ times/day to $>20$ times/day and ratios in most studies ranging from 1.8-3.0 (Tables 1,2 , 3). Two follow-up studies reported non-significant ratios at follow-up for handwashing $>10$ times/day (Uter et al. 1999a) and $>20$ times/day (Bauer et al. 1998) (Table 2).

The duration of daily wet work has less consistently been associated to ICD. Uter et al. (1999b) in a follow-up study of German hairdressing apprentices reported especially unprotected wet work $>2 \mathrm{~h}$ per day to be significantly associated with HE, with OR increasing from 1.6 when using gloves to 1.8 without gloves. Douwes et al. (2017) in a study of cleaners also reported a dose-response relation between self-reported HE and duration of daily exposure to water without gloves. Similar significant and insignificant trends suggestive of a dose-response effect have been shown in a number of cross-sectional or follow-up studies in cleaning and other industries in which handwashing has been registered as number of hours per day or week (Tables 2, 3).

In contrast among HCW, Lan et al. (2011) in an observational study of exposure and Ibler et al. (2012) in their study reported no association of HE to duration of daily handwashing.

\section{Conclusion}

The available evidence from epidemiological studies supports an association between wet work, especially frequent wet work and mostly minor ICD. No threshold level can be described. The level of evidence is considered strong $(+++)$. Results from the presented studies of exposure restricted to disinfectants and detergents vary. Evidence from combined exposure to water, probably the case for multiple studies on wet work exposure where these exposures cannot be separated, indicates detergents especially industrial surfactants and non-alcoholic disinfectants as an important cause of ICD. The overall evidence of a causal association between ICD and exposure to detergent and disinfectants is considered moderate $(++)$, while the overall evidence combined with other wet work is considered strong $(+++)$.

\section{Exposure to gloves}

\section{Design}

Exposure to gloves and outcomes related to ICD were reported in 14 epidemiological studies, including 10 studies also described in the section concerning wet work (Tables 1 , 2, 3). Occupations included studies in HCW (8), cleaning (2), hairdresser apprentices (1), workers in a rubber-manufacturing plant (1), and clean-room workers in a semiconductor production company (2). One study was a followup study (Uter et al. 1999a), the remaining cross-sectional studies.

\section{Exposure source and measurement}

In one study, exposure assessment to gloves was based on observations (Lan et al. 2011) and in another study recorded on diary cards (Visser et al. 2014b). In studies of clean-room workers, all workers were considered exposed to occlusive gloves during all work hours (Weistenhofer et al. 2015, 2017). The remaining studies relied on self-reported exposure of number of hours per day.

\section{Outcome}

Six studies included clinical verified diagnosis, two of which also included patch tests (Stingeni et al. 1995, 1996). In five studies, diagnosis was self-reported $\mathrm{HE}$ in the past 3 or 12 months. Three studies relied on self-reported symptoms (Table 3).

\section{Quality of the studies}

Possible selection bias in the cross-sectional studies reporting adverse effects of glove wearing is a major risk factor, as a reverse causation cannot be ruled out.

Use of gloves, especially rubber gloves, is also a risk factor for ACD and use of natural rubber gloves a risk factor for $\mathrm{CU}$. For general methodological issues, we refer to this section in the paragraph on wet exposure.

Overall, four studies are graded as high quality (Lan et al. 2011; Uter et al. 1999a; Weistenhofer et al. 2017, 2015), five medium quality (Douwes et al. 2017; Hamnerius et al. 2018; Lee et al. 2013; Vermeulen et al. 2001; Visser et al. 2014b), and the remaining low quality.

\section{Results}

Stingeni et al. (1995) reported results from two studies of employees from the same hospital who were clinically examined including patch tests. In the first study, they found a 
high frequency of OCD (21\%) and IOCD in 95\% of cases (Stingeni et al. 1995). In the second study, which only included workers using latex gloves, ICD was diagnosed in $13 \%$, by a positive "user test". After testing with two types of latex gloves, they found $36 \%$ of cases to be associated with corn starch powder, and $28 \%$ with corn starch and/or latex-protein (Stingeni et al. 1996). Hamnerius et al. (2018) in a Swedish study examined self-reported HE among more than $9000 \mathrm{HCW}$. They found a dose-dependent association between HE and the duration of daily glove use: OR 1.5 $(1.1-1.8)$ for the highest exposure category of more than $3 \mathrm{~h} /$ day, but no association with frequency of glove use.

Three studies on cleaners (Nielsen 1996) and HCW (Flyvholm et al. 2007; Lee et al. 2013) reported positive associations between use of gloves and increased risk of selfreported symptoms of HE, corresponding to an increased OR of 1.87 for self-reported HE with use of protective gloves (Flyvholm et al. 2007) and of 1.99 for wearing of gloves more than $5 \mathrm{~min}$ per use but with no association with frequency of glove use (Lee et al. 2013). By contrast, no increased risk for ICD was reported in six studies (Douwes et al. 2017; Uter et al. 1999a; Vermeulen et al. 2001; Visser et al. 2014b; Weistenhofer et al. 2015, 2017).

Uter et al. (1999a) in a follow-up-study on hairdressing apprentices reported a protective effect on HE with use of gloves for more than $2 \mathrm{~h}$ per day.

Weistenhofer et al. (2017); (2015) performed two studies, 1 year apart, at the same company in 177 and 277 cleanroom workers using occlusive nitrile gloves for most of their work shift, compared to reference workers with no glove exposure. In both studies, they reported that clean-room workers had an increased frequency of self-reported workrelated skin problems, but no difference in clinical hand eczema score (HEROS).

Vermeulen et al. (2001) found no association between glove use and clinical diagnosed HE or minor dermatitis among rubber-manufacturing workers. Neither did four studies on self-reported HE among HCW (Ibler et al. 2012; Lan et al. 2011; Visser et al. 2014b) or cleaners (Douwes et al. 2017), which in the study by Lan et al. (2011) included observations of glove use.

\section{Conclusion}

The studies on glove exposure vary with only slightly increased ICD in the studies of highest quality. While some studies have mainly shown positive effects of glove use in relation to $\mathrm{HE}$, other studies have revealed associations between HE/ICD and daily use of gloves, i.e., a clinically negative effect of gloves use.

The overall evidence of a causal association between ICD and occlusive glove exposure without other irritant exposures is considered limited $(+)$.
The overall evidence of a causal association between ICD and occlusive gloves combined with other irritant exposure is considered moderate $(++)$.

\section{Metals, metalworking fluids, and oils}

\section{Design}

Exposure to MWF and outcomes related to ICD were reported in seven epidemiological studies, one follow-up study, three nested case-control studies within follow-up studies, and three cross-sectional studies.

Five studies were from different kinds of metalworking factories and one from a car manufacturing industry. The sevent study was a case-control study within a population cohort.

\section{Exposure, source, and measure}

Two studies used an external control group, and the remaining relied on exposure contrast within the exposed groups, based on expert evaluation of individual job risk factors with or without work diaries (Berndt et al. 2000; Jee et al. 1986). In a large study in a hard-metal production facility, the exposure to cutting oils and fluids relied on observations on work tasks on the day of examinations (Fischer and Rystedt 1985). Two studies relied on self-reported exposure intensity (Apfelbacher et al. 2010; Mirabelli et al. 2009).

Five studies reported exposure to MWF, oil-based MWF (Goh and Gan 1994), combined with water-based MWF (Berndt et al. 2000; de Boer et al. 1989), and with mechanical exposures representing mechanical friction (Berndt et al. 2000; Mirabelli et al. 2009).

\section{Outcome}

Diagnosis of outcome was clinically assessed in all but one study and included patch test in three studies and all provided some information on criteria for diagnosis or grading of diagnosis. Three studies included varying degrees of minor irritant reactions, including typically slight erythema, dryness, and chapping. One study used the definition "clinical dermatoses" combining minor changes and eczema; three reported on clinically ICD. In one study, outcome relied solely on self-reported symptoms of a rash (Mirabelli et al. 2009). 


\section{Quality of the studies}

General methodological issues regarding risk of selction bias, miclassification of outcome, and exposure were election bias applied as in the section on exposure to wet work.

Overall one study was regarded as high quality (Berndt et al. 2000), three studies as medium quality, and two as low quality (Fischer and Rystedt 1985; Goh and Gan 1994).

\section{Results}

Exposure to kerosene was only reported in one study of medium quality. In this study, there was a very high prevalence of clinical dermatoses including ( $84 \%$ of the workers), with a a prevalence ratio of 5.5 compared to reference workers, while no differences suggesting a dose-response relation could be found when comparing high exposed with low exposed (Jee et al. 1986).

One large 2.5-year prospective study of Swiss metalworker trainees in a nested case-control design reported associations between lack of rest days, mechanical work, and exposure to cleaning agents containing solvents, while there was no separate effect of exposure to MWF or metal dust (Berndt et al. 2000).

Another nested case-control study in the car industry could not demonstrate any significant effect of exposure to metal-related work exposures (Apfelbacher et al. 2010).

The remaining three studies reported increased risk of generally mild HE, with prevalence ratios ranging from 1.2 to 3.7 (de Boer et al. 1989; Fischer and Rystedt 1985), and in one study point prevalences up to $78 \%$ were found in exposed compared to none in reference workers (Goh and Gan 1994).

No studies reported on dose-response relation between exposure to MWF and irritant skin changes.

\section{Conclusion}

The available evidence from epidemiological studies supports a moderate level of association $(++)$, between MWF and mainly minor ICD.

\section{Mechanical exposures}

\section{Design}

Mechanical exposure related to irritant skin reactions was reported in four industry-based, one nested case-control study within a follow-up study and three cross-sectional studies (Tables 1,2,3). Two of the studies were from the metalworking industry and have also been included in the section on
MWF and two were from the construction industry involving exposure to airborne man-made mineral fibers (MMMF).

\section{Exposure, source, and measurement}

Measurements of dust exposure with diameters of the ceramic fibers were performed in one study (Kiec-Swierczynska and Wojtczak 2000). In the other construction study, exposure to MMMF was self-reported (Petersen and Sabroe 1991). One study by Berndt et al. (2000) included expert-based semiquantitative exposure assessments, while Fischer and Rystedt (1985) collected present exposure by observation.

\section{Outcome}

Diagnosis of ICD and irritant reactions were based on clinical examinations in three studies, including patch test in two studies, and self-reported eczema and symptoms in the fourth study. All studies provided some information on criteria for diagnosis of ICD/HE and/or irritant symptoms.

\section{Quality of the studies}

The three cross-sectional studies are prone to selection bias. Misclassification of both exposure and outcome was most likely in the study by Petersen and Sabroe (1991), which relied solely on self-reported data, and in the study by Fischer and Rystedt (1985) which did not distinguish mechanical exposure of metal and powders from cutting fluids. Overall, two of the studies was evaluated as being of high quality (Berndt et al. 2000; Kiec-Swierczynska and Wojtczak 2000); one of medium quality and one of low quality.

\section{Results}

Kiec-Swierczynska and Wojtczak (2000) found increased prevalence of both acute and chronic ICD among workers exposed to MMMF, corresponding to an overall prevalence ratio for ICD of $6.9^{*}$ (2.3-20.8) compared to non-exposed, and a patch test with the ceramic fibers confirming irritancy of the fibers. Petersen and Sabroe (1991) reported a dose-response relation between exposure to MMMF and self-reported eczema and itching of the skin.

In the studies of metalworkers, the nested case-control study reported a non-significant trend for a dose-response association between hours of daily mechanical work and incident cases of mild HE (Berndt et al. 2000), while the cross-sectional study described an increased prevalence of irritant reactions, prevalence ratio 3.7* (2.7-4.9) (Fischer and Rystedt 1985). 


\section{Conclusion}

The reported epidemiological documentation for ICD and skin irritation due to mechanical irritation among workers is scarce. The few published studies do not allow for a firm conclusion, and the evidence of a causal association is therefore limited $(+)$.

\section{Prognosis of ICD}

\section{Design}

Epidemiological studies on prognosis of OCD including OICD, with focus on healing or improvement, were reported in 13 papers from 10 prospective studies and one retrospective cohort study (Table 4).

The studies were based on follow-up of clinically diagnosed cases by dermatologist and/or occupational physician (Adisesh et al. 2002) or nationally notified recognized cases.

Eight studies concerned patients from a broad specter of various industries. Three studies focused on workers from specific industries: the food industry, a metal processing plant, and hairdressers.

The follow-up time in the studies ranged from 0.3 to 16 years, but most had fairly short follow-up periods of $1 / 2-1$ year and up to 5 years.

\section{Exposures and occupational variables influencing prognosis}

The main outcome of interest was the prognosis of OICD in relation to change in exposure, i.e., change to another job or work tasks. Self-reported changes were reported in ten studies. Among these were one study with focus on the influence of self-reported current exposure and two studies that included the duration of exposure prior to diagnosis.

\section{Prognostic outcomes}

As measurement of prognosis of OCD, the majority of studies used either healing vs persistence and/or various degrees of improvement of skin reactions. One study reported prognostic outcome in severity scores (Jungbauer et al. 2004b).

Prognostic outcome was based on clinical examinations in two studies (Adisesh et al. 2002; Lindemayr 1984), while in one study, clinical assesment of healing was performed on a subgroup of patients (Chia 1991). In the remaining studies, outcome was self-reported.

\section{Quality of the studies}

Low rate of participation at follow-up in four of the studies or missing information on outcome in one study (Lindemayr 1984) may pose the risk of selection bias.

Information on job change, or change of work tasks and the prognostic outcome, was self-reported in most of studies and may present a risk of misclassification of exposure and outcome, probably non-differential. This could lead to an underestimation of beneficial effects of work change if workers who had to change jobs are more likely to report a worse prognosis.

Overall, three studies were graded as high quality (Caroe et al. 2018b; Cvetkovski et al. 2006; Malkonen et al. 2010), four of medium quality, and the remaining of low quality (Table S3).

\section{Results}

The overall proportion of healed ICD varied from 18 to $72 \%$, and the proportion of improved ICD varied from 41 to $84 \%$.

Five studies reported a more favorable prognosis for healing of OCD including ICD for workers who changed occupation (Caroe et al. 2018a, 2018b; Malkonen et al. 2010; Rosen and Freeman 1993) and/or work task (Malkonen et al. 2009; Rosen and Freeman 1993 Australia). Another four studies reported no association between healing and change of occupation (Chia 1991; Keczkes et al. 1983; Lindemayr 1984; Shah et al. 1996).

Malkonen et al. (2010) in a Finnish study that included 251 patients with ICD with a mean follow-up time of 10.5 years reported healing in ICD of $35 \%$ with no difference with regard to ACD. Lack of healing was associated with no change of occupation, OR 1.55 (1.03-2.34) and with a dose-response relation to duration of OCD prior to diagnosis. In a large Danish study of workers with OCD with a sub-cohort of 954 workers with ICD due to wet work, Caroe et al. (2018b), (2018c) reported healing and improvement of OCD associated with change of profession or non-employment 4-5 years after diagnosis, with no difference between ICD and ACD. The overall healing of ICD or improvement of ICD was $15 \%$ and $52 \%$, respective, among those who stayed in the same profession, $19 \%$ and $67 \%$ for those who changed profession, and $28 \%$ and $61 \%$ for those who were outside the labor marked at follow-up. Compared to workers who stayed in their professions, the OR for improvement of ICD was 2.13 (1.49-3.05) for workers who left their professions and 1.79 (1.19-2.70) for those without a job. They found inverse dose-response relations at follow-up between hours spent with wet work as well as frequency of handwashing and healing/improvement of ICD. Each step down 
in categories of exposure increased the chance of healing by $25 \%$ and $34 \%$ and of improvement by $4 \%$ and $8 \%$.

Another Danish study based on recognized OHE cases, where almost $50 \%$ had left their job, demonstrated an overall 1 year improvement rate of $41 \%$ and a strong association between baseline severity of OCD and job loss, but no association to job change or duration of OCD (Cvetkovski et al. 2006).

Rosen and Freeman (1993) reported an overall prevalence of healing for $34 \%$ and improvement among $70 \%$ in an Australian study of 334 patients $1-5$ years after diagnoses of $\mathrm{OCD}$, with no difference between ICD and ACD. Healing or improvement was reported in $43 \%$ and $76 \%$ among patients who changed industry, compared to $28 \%$ and $67 \%$ for workers staying in the same industry - the RR* of healing was $1.6(1.2-2.1)$. This study also reported a more favorable prognosis of workers who stayed in the industry and changed work task (Table 4).

In two studies reporting on the effect of exposure duration prior to diagnosis. Adisesh et al. (2002) found non-improvement of the eczema associated with a higher exposure duration among non-atopics, while Chia (1991) found no association between duration of exposure and healing of ICD.

\section{Conclusion}

Results should be interpreted with caution as most of the included studies were performed on selected populations of patients. Therefore, they probably represent only the most severe cases, and may not be representative for the prognosis of less severe ICD in individuals not seeking specialist medical attention.

With these reservations, the available evidence from epidemiological studies supports a poor prognosis for improvement with complete healing of OCD including ICD if no or non-specific preventive measures are undertaken - the level of evidence was assessed to be strong $(+++)$. The literature supports a better prognosis of complete healing of ICD when reduced exposure is achived by change of occupation or work task, with the level of evidence being moderate $(++)$.

Although a greater proportion of individuals will naturally experience improvement rather than complete healing, quality studies focusing on improvement were sparse and with conflicting information, and the level of evidence found to be limited (+).

The level of evidence for an association between long duration of exposure prior to diagnosis and subsequent continuous ICD was limited because of to few studies and conflicting results $(+)$.

\section{Discussion}

\section{Summary of main results}

We identified and reported results and made quality assessment of 55 epidemiological papers from 48 studies presenting occupational risk factors for ICD and the prognosis of ICD and in addition included supplementary documentation from experimental studies.

Concerning wet work exposure, the available evidence supports an association between wet work and minor ICD in combination with other irritants. No threshold limit could be described. The level of evidence was considered strong $(+++)$.

When, however, exposure was focused on disinfectants and detergents, often in combination with wet work, the overall evidence for a causal association with ICD was considered moderate $(++)$, while the overall evidence for detergent and non-alcoholic disinfectants in combination with general wet work was assessed to be strong $(+++)$.

The overall evidence for a causal association between occlusive glove exposure without other irritants, and ICD, was considered limited $(+)$, while the evidence for a causal association related to a combination of occlusive gloves and other irritant exposure was considered moderate $(++)$.

The evidence for a causal association between exposures to MWF and ICD was considered moderate $(++)$, and the overall evidence for a causal association between mechanical exposures and ICD was considered limited $(+)$.

Regarding the outcome of efforts to heal OICD, the included epidemiological studies support a poor prognosis for complete healing after no or non-specific preventive measures in the work environment, with the level of evidence being strong $(+++)$. A better prognosis for complete healing was found when exposure was ceased due to change of work task - the level of evidence was moderate $(++)$.

While more individuals in the clinical setting experience partial remission rather than complete healing, the studies investigating improvement of OICD in relation to change of occupation or work tasks are inconclusive and evidence is considered limited (+).

\section{Misclassification of exposure}

Since the risk of OICD is expected to be dose-dependent, quantitative onsite exposure information is preferred to qualitative information, reducing the likelyhood of reporting bias which would eventually lead to risk estimates biased toward no effect due to dilution of exposure.

Most of the studies, however, relied on self-reported exposures. Only three studies provided independent quantitative 
measurements or observations (Daftarian et al. 2002; KiecSwierczynska and Wojtczak 2000; Lan et al. 2011), and in three other studies, semi-quantitative exposure assessment was performed by experts or based on self-reported exposures reported in diary cards (Berndt et al. 2000; Jee et al. 1986; Visser et al. 2014b).

Some of the studies relied solely on comparisons between different work groups, e.g., hospital departments, without providing further information regarding the extend of the on exposure - they can primarily be used for hypothesis generation.

A study by Jungbauer et al. (2004a) compared questionnaire and observation-based information regarding wet work, and found that the duration of exposure was overestimated by a factor of approximately two, while the frequency of exposure to wet work was underestimated by about the same factor. The same trend was found by Lund et al. (2019) in professions with a high frequency of wet work; they reported a low validity of self-reported wet work exposures, with sensitivity of $50 \%$ and specificity of $60 \%$.

The implication of theese type of non-differential misclassification will probably result in attenuation of the risk of exposure when reported as dichomeous exposure, i.e., wet work more than $2 \mathrm{~h} /$ day, while a more detailed analysis showing a dose-response relation would underestimate the risk at lower exposures, because the reported risk would start at a higher exposure than revealed by the actual measurements.

Likewise as self-reported frequencies of exposures are probably underreported, the actual risk would be from higher actual frequencies than reported in the studies.

Two other studies compared observations and self-assessment of exposures to water, gloves, hand disinfectants, and moisturizers among nurses and a mixed group of mechanics, kitchen, and office workers, and reported a tendency to overestimate all exposures (Anveden et al. 2006; Anveden and Meding 2007).

\section{Misclassification of outcome}

A non-differential misclassification of outcome case definitions for ICD with low specificity and overreporting of disease could be expected to dilute any real associations with exposure toward the null, while studies with low sensitivity and underestimation of the disease could be expected not to affect relative risk of disease in relation to exposure, but reduces risk differences (Rothman et al. 2008). Selfreported questionnaire-based HE or symptoms of HE have been validated against clinical examinations in several studies, revealing that self-reported HE tended to underestimate the prevalence of clinical HE in studies with low sensitivity and high specificity, whereas the prevalence of HE based on self-reported symptoms tended to overestimate the prevalence of HE in studies with high sensitivity and low specificity (Carstensen et al. 2006; Livesley et al. 2002; Meding and Barregard 2001; Smit et al. 1992). Bregnhoj et al. (2011b) have recently validated self-reported HE by the Nordic Occupational Skin Questionnaire NOSQ-2002 used by several of the studies reported in this review. In a study, among Danish hairdressing apprentices comparing self-reported against clinical examination, they reported a good agreement, with a sensitivity of $70.3 \%$, specificity of 99.8\% and positive/negative predictive values of $96.3 / 98.5 \%$.

No gold standard for a definition of ICD or irritant HE exists, and in most studies, case definitions of ICD have typically been made clinically as an exclusion diagnosis based on no finding of ACD and an assumed temporal relation to a history of a supposed relevant irritant exposure (Ale and Maibach 2014; Friis et al. 2014). In recent years, however, as discussed by Friis et al. (2014); Schwensen et al. (2014), diagnostic criteria for the diagnosis of ICD and combined ICD and ACD have changed and are now defined by significant exposures to known irritants and the temporal relationship between exposure and the dermatitis, the German wet work criteria as described in the background section. Theese authors also discuss the fundamental problem that the diagnostic criteria for ICD are based on known risk factors and not a valid test, resulting in a mixing of exposures and thus a risk of overestimation of the occurrence of ICD in occupational settings with high exposures to irritants.

Another drawback when exposure is included in the diagnostic criteria is difficulties in determination of exposure response relations in different studies that use different definitions of ICD. This is the case when some studies report on major dermatitis resembling eczema and other minor changes/irritant reactions.

Furthermore, ICD is suspected to play a role in the development of ACD. As dysfunction of the skin barrier is a main feature of any $\mathrm{CD}$, it is reasonable to assume that this disruption may result in increased secondary sensitization rates to allergens, facilitating secondary ACD (Lee et al. 2013).

\section{Supplementary experimental evidence}

In addition to epidemiological studies, experimental studies have been demonstrated to be relevant. Assessment of the irritant potential of chemicals has been investigated trough different methods including visual scoring, transepidermal water loss, laser-Doppler flowmetry and skin color reflectance (Kartono and Maibach 2006). Slotosch et al. (2007) studied the effects of propanol-based disinfectants and detergents on skin irritation, and reported more irritation and barrier disruption for sodium lauryl sulfate (SLS) than for the alcohol-based hand rub and a protective effect of combined use of SLS and disinfectants. A study by Pedersen et al. (2005) found an increased irritant response for detergent as 
compared to disinfectants alone and disinfectants combined with detergents after daily repeated application of detergents, alcohol-based disinfectants, and detergents/disinfectants.

Regarding gloves, supplementary evidence of experimental studise was gathered in a review by Tiedemann et al. (2015). They concluded that the negative effect of occlusion in itself is limited and that only extensive and long-term occlusion will cause barrier impairment.

For mehcanical exposure to fibers evidence in an experimental setting has been provided by Tsunoda et al. (2014). In a study on volunteers that underwent $24 \mathrm{~h}$ of provocation with different continuous glass filament, only transient skin reactions were observed, while no changes were visible after $24 \mathrm{~h}$.

\section{Atopy and other pre-existing non-occupational factors}

Atopic disposition is a well-known vulnerability factor for susceptibility to ICD, with increased OR of around a factor of 3 , when the severity corresponds to medically treated atopic disease. Consequently, accounting for atopy, at best in adjusted analyses, has been included in our quality assessment of the studies. However, when it comes to an exposure-response outcome, there was not a substantial difference between studies including information about atopy, and those that did not. In fact, some studies after adjustments for atopy showed stronger associations between exposure to irritants and ICD (Callahan et al. 2013; Visser et al. 2014a). In addition, some studies have indicated a healthy worker effect, fewer susceptible workers entering the work areas with irritant exposures (Bandier et al. 2013; Bregnhoj et al. 2011a). This is in accordance with the common clinical advice given to atopic individuals not to enter risk-trades.

Gender and age were included in most of the studies, but while some studies reported association to female gender and young age, inclusion of those parameters in the analyses in general, did not provide substantial evidence of changes in the effect of occupational irritant exposures. Therefore, an inverse relationship to age, as demonstrated in some studies, could not be confirmed on this review.

Private exposures (housework and domestic childcare) could be relevant additional exposures, which might contribute to the overall exposure burden of irritants along with occupational exposures. However, only a few studies included domestic exposures. While some reported childcare or housework to be significant risk factors for ICD (Bauer et al. 2001; Ibler et al. 2012; Mortz et al. 2014), others fund no association (Held et al. 2001; Lan et al. 2011; Lee et al. 2013) and the available evidence does not allow for estimation of the effect of such exposures (Table S-3 in the online supplementary list details on original studies with focus on individual risk factors).

\section{Strength and limitations}

Although the literature search was broad and performed in several databases, we may have missed studies of relevance not published in peer-reviewed journals or not indexed to accommodate our search strategy. The literature search covers a 40-year period of time and was updated until March 2020.

We were not able to perform any meta-analyses due to differences in the reported outcomes.

To obtain enough information on associations between ICD and irritants, we included studies with very different designs, measures of exposures, diagnostic criteria, and sources of the diagnosis of ICD. We found that many studies were influenced by information bias, resulting in misclassifications of exposure and diagnosis. In most cases, these misclassifications were, however, non-differential causing attenuation of exposure disease associations with smaller effects than would be expected without misclassification. However, differential misclassification might also be present due to the incorporation of exposure in the diagnosis of ICD and this could tend to overestimate risk of ICD in groups with expected higher exposures to irritants, e.g.. wet work, also in studies where ICD has been diagnosed clinically.

The direction of bias due to misclassification could likely cause lower disease association than would be the case without incorrect classifications.

Private exposure from household or leisure time activities is included in only a few studies; this unadjusted additional exposure would tend to overestimate the effect from occupational exposure.

\section{Conclusion}

This review provides strong evidence for associations between irritant exposures and the development of OICD in relation to wet work exposure, with or without combined exposure to detergent and disinfectants. The evidence for metalwork exposures was moderate and limited for exposure to mechanical exposures and gloves. Furthermore, this review provides strong evidence for a poor prognosis of complete healing when exposure continues unchanged, and moderate evidence for a complete healing with cessation or decrease of exposure. Only a few studies investigated improvement rather than complete healing and the results were variable, and therefore, the evidence of partial improvement of ICD in relation to occupational changes was limited.

However, there were few high-quality studies and a number of limitations affected all the included studies in varying degree, making comparison and summation of evidence 
difficult. These limitations included low diagnostic specificity, non-quantitative exposure information, lack of exposure response data, and to some extent limited confounder adjustment, with atopy presumeably being the most important potential confounder.

The bulk of studies had a cross-sectional design, and there is a need of follow-up studies focusing on ICD with concomitant quantitative exposure assessment and assessment of ICD using well-defined clinical measures.

Wet work is the most prevalent exposure, giving rise to the highest occurrences of absolute numbers of OICD, and occupations with frequent wet work exposure, e.g., in the health and social care sectors, will be increasing in the coming years. Danish hospital nurses typically performed handwashing procedures some $30-40$ times per day, but at many hospitals, hand wash with soap is now reduced to less than 4-5 times per day, while the hand hygeine is based on alcoholic disinfectants only. Regarding glove use, we are not able to give specific advise with regard to either the preventive potential or the risk factor in itself. Robust knowledge of prognostic factors is important for clinical practice and should be subject to further studies.

Supplementary Information The online version contains supplementary material available at https://doi.org/10.1007/s00420-021-01781-0.

Acknowledgements The authors would like to thank Marianne Kyndi and Rasmus Boe Mortensen for contributing in the literature selection.

Funding The study was funded by the Danish Working Environment Research Fund [\#56-2015-03/20150018092].

\section{Declarations}

Conflict of interest The authors have no conflicts of interest to declare that are relevant to the content of this review.

Data sharing statement Request for access to data should be addressed to the corresponding author: gitte.hojbjerg.jacobsen@rsyd.dk.

Open Access This article is licensed under a Creative Commons Attribution 4.0 International License, which permits use, sharing, adaptation, distribution and reproduction in any medium or format, as long as you give appropriate credit to the original author(s) and the source, provide a link to the Creative Commons licence, and indicate if changes were made. The images or other third party material in this article are included in the article's Creative Commons licence, unless indicated otherwise in a credit line to the material. If material is not included in the article's Creative Commons licence and your intended use is not permitted by statutory regulation or exceeds the permitted use, you will need to obtain permission directly from the copyright holder. To view a copy of this licence, visit http://creativecommons.org/licenses/by/4.0/.

\section{References}

Adisesh A, Meyer JD, Cherry NM (2002) Prognosis and work absence due to occupational contact dermatitis. Contact Dermat 46(5):273-279 (cod460505[pii])

AES (2016) Erhvervssygdomme opgjort på diagnose 2011-2015. Arbejdsmarkedets Erhvervssikring;

Agner $\mathrm{T}$ et al (2015) Classification of hand eczema. J Eur Acad Dermatol Venereol JEADV 29(12):2417-2422. https://doi.org/10. $1111 / j d v .13308$

Ale IS, Maibach HI (2014) Irritant contact dermatitis. Rev Environ Health 29(3):195-206

Anveden I, Meding B (2007) Skin exposure in geriatric care-a comparison between observation and self-assessment of exposure. Contact Dermat 57(4):253-258 (COD1211[pii])

Anveden I, Liden C, Alderling M, Meding B (2006) Self-reported skin exposure-validation of questions by observation. Contact Dermat 55(3):186-191 (COD907[pii])

Anveden Berglind I, Alderling M, Jarvholm B, Liden C, Meding B (2009) Occupational skin exposure to water: a populationbased study. Br J Dermatol 160(3):616-621. https://doi.org/10. 1111/j.1365-2133.2008.08850.x

Apfelbacher CJ, Funke U, Radulescu M, Diepgen TL (2010) Determinants of current hand eczema: results from case-control studies nested in the PACO follow-up study (PACO II). Contact Dermat 62(6):363-370. https://doi.org/10.1111/j.1600-0536. 2010.01729.x

Avnstorp C (1991) Risk factors for cement eczema. Contact Dermat 25(2):81-88

Bandier J et al (2013) Carriers of filaggrin gene (FLG) mutations avoid professional exposure to irritants in adulthood. Contact Dermat 69(6):355-362. https://doi.org/10.1111/cod.12097

BAuA (2008) Risks resulting from skin contact -identification, assessment, measures. TRGS 401. vol 2016. Bundesanstalt für Arbeitsschutz und Arbeitsmedizin (BAuA). http://www.baua. de/en/Topics-from-A-to-Z/Hazardous-Substances/TRGS/pdf/ TRGS-401.pdf?_blob=publicationFile $\& v=6$

Bauer A et al (1998) Development of occupational skin diseases during vocational training in baker and confectioner apprentices: a follow-up study. Contact Dermat 39(6):307-311

Bauer A et al (2001) Occupational hand dermatitis in food industry apprentices: results of a 3-year follow-up cohort study. Int Arch Occup Environ Health 74(6):437-442

Bauer A et al (2018) Interventions for preventing occupational irritant hand dermatitis. Cochrane Database Syst Rev 4:4414. https://doi.org/10.1002/14651858.CD004414.pub3

Beer C et al. (2015) Exposure to quartz dust/sand (crystalline silica) and the risk of development of connective tissue diseases (for instance scleroderma) and kidney diseases (for instance glomerulonephritis). vol 2017. Arbejdsmarkedets Erhvervssikring

Berndt U, Hinnen U, Iliev D, Elsner P (2000) Hand eczema in metalworker trainees - an analysis of risk factors. Contact Dermat 43(6):327-332

Bregnhoj A, Sosted H, Menne T, Johansen JD (2011a) Healthy worker effect in hairdressing apprentices. Contact Dermat 64(2):80-84. https://doi.org/10.1111/j.1600-0536.2010. 01831.x

Bregnhoj A, Sosted H, Menne T, Johansen JD (2011b) Validation of self-reporting of hand eczema among Danish hairdressing apprentices. Contact Dermat 65(3):146-150. https://doi.org/10. 1111/j.1600-0536.2011.01908.x

Callahan A et al (2013) Winter season, frequent hand washing, and irritant patch test reactions to detergents are associated with hand dermatitis in health care workers. Dermat Contact Atopic Occup 
Drug 24(4):170-175. https://doi.org/10.1097/DER.0b013e3182 $90 \mathrm{c} 57 \mathrm{f}$

Caroe TK, Ebbehoj N, Agner T (2014) A survey of exposures related to recognized occupational contact dermatitis in Denmark in 2010. Contact Dermat 70(1):56-62. https://doi.org/10.1111/cod.12134

Caroe TK, Ebbehoj NE, Bonde JP, Agner T (2018a) Occupational hand eczema and/or contact urticaria: factors associated with change of profession or not remaining in the workforce. Contact Dermat 78(1):55-63. https://doi.org/10.1111/cod.12869

Caroe TK, Ebbehoj NE, Bonde JPE, Flachs EM, Agner T (2018b) Hand eczema and wet work: dose-response relationship and effect of leaving the profession. Contact Dermat 78(5):341-347. https:// doi.org/10.1111/cod.12934

Caroe TK, Ebbehoj NE, Bonde JPE, Vejlstrup SG, Agner T (2018c) Job change facilitates healing in a cohort of patients with occupational hand eczema. Br J Dermatol 179(1):80-87. https://doi. org/10.1111/bjd.16095

Carstensen O, Rasmussen K, Ponten A, Gruvberger B, Isaksson M, Bruze M (2006) The validity of a questionnaire-based epidemiological study of occupational dermatosis. Contact Dermat 55(5):295-300 (COD920[pii])

Chia Group (1991) Prognosis of occupational dermatitis in Singapore workers. Am J Contact Dermat 2(2):105-109

Chou TC, Sheu HM, Chiu JE, Wu JD, Shih TS, Chang HY (2004) Combined exposure to carbon disulfide and sulfuric acid simultaneously increases the risk of hand dermatitis in rayon industry. J Expo Anal Environ Epidemiol 14(7):551-557. https://doi.org/ 10.1038/sj.jea.7500385

Coenraads PJ, Diepgen TL (1998) Risk for hand eczema in employees with past or present atopic dermatitis. Int Arch Occup Environ Health 71(1):7-13

Cvetkovski RS, Zachariae R, Jensen H, Olsen J, Johansen JD, Agner T (2006) Prognosis of occupational hand eczema: a follow-up study. Arch Dermatol 142(3):305-311

Daftarian HS, Lushniak BD, Reh CM, Lewis DM (2002) Evaluation of self-reported skin problems among workers exposed to toluene diisocyanate (TDI) at a foam manufacturing facility. J Occup Environ Med Am Coll Occup Environ Med 44(12):1197-1202

Davis JA, Visscher MO, Wickett RR, Hoath SB (2010) Influence of tumour necrosis factor-alpha polymorphism-308 and atopy on irritant contact dermatitis in healthcare workers. Contact Dermat 63(6):320-332. https://doi.org/10.1111/j.1600-0536.2010. 01778.x

de Boer EM, van Ketel WG, Bruynzeel DP (1989) Dermatoses in metal workers. (I). Irritant contact dermatitis. Contact Dermat 20(3):212-218

de Jongh CM et al (2008) Loss-of-function polymorphisms in the filaggrin gene are associated with an increased susceptibility to chronic irritant contact dermatitis: a case-control study. $\mathrm{Br} \mathbf{J}$ Dermatol 159(3):621-627. https://doi.org/10.1111/j.1365-2133. 2008.08730.x

Dickel H, Bruckner T, Bernhard-Klimt C, Koch T, Scheidt R, Diepgen TL (2002a) Surveillance scheme for occupational skin disease in the Saarland, FRG. First report from BKH-s. Contact Dermat 46(4): 197-206

Dickel H, Kuss O, Schmidt A, Kretz J, Diepgen TL (2002b) Importance of irritant contact dermatitis in occupational skin disease. Am J Clin Dermatol 3(4):283-289

Diepgen TL (2003) Occupational skin-disease data in Europe. Int Arch Occup Environ Health 76(5):331-338. https://doi.org/10.1007/ s00420-002-0418-1

Diepgen TL, Coenraads PJ (1995) What can we learn from epidemiological studies on irritant contact dermatitis? Curr Probl Dermatol 23:18-27
Diepgen TL, Coenraads PJ (1999) The epidemiology of occupational contact dermatitis. Int Arch Occup Environ Health 72(8):496-506

Diepgen TL et al (2009) Hand eczema classification: a cross-sectional, multicentre study of the aetiology and morphology of hand eczema. Br J Dermatol 160(2):353-358. https://doi.org/10. 1111/j.1365-2133.2008.08907.x

Diepgen TL et al (2015) Guidelines for diagnosis, prevention and treatment of hand eczema. J Der Deutschen Dermatol Gesellschaft J German Soc Dermatol JDDG 13(1):1-22

Douwes J et al (2017) Determinants of hand dermatitis, urticaria and loss of skin barrier function in professional cleaners in New Zealand. Int J Occup Environ Health 23(2):110-119. https://doi.org/ $10.1080 / 10773525.2018 .1427307$

ESCD (2020) What is contact dermatitis? European Society of contact dermatitis. https://www.escd.org/contact-dermatitis/what-iscontact-dermatitis/

Fischer T, Rystedt I (1985) Hand eczema among hard-metal workers. Am J Ind Med 8(4-5):381-394

Flyvholm MA, Bach B, Rose M, Jepsen KF (2007) Self-reported hand eczema in a hospital population. Contact Dermat 57(2):110-115

Friis UF, Menne T, Schwensen JF, Flyvholm MA, Bonde JP, Johansen JD (2014) Occupational irritant contact dermatitis diagnosed by analysis of contact irritants and allergens in the work environment. Contact Dermat 71(6):364-370. https://doi.org/10.1111/ cod. 12290

Goh CL, Gan SL (1994) The incidence of cutting fluid dermatitis among metalworkers in a metal fabrication factory: a prospective study. Contact Dermat 31(2):111-115

Guo YL, Wang BJ, Lee JY, Chou SY (1994) Occupational hand dermatoses of hairdressers in Tainan City. Occup Environ Med 51(10):689-692

Hamnerius N, Svedman C, Bergendorff O, Bjork J, Bruze M, Ponten A (2018) Wet work exposure and hand eczema among healthcare workers: a cross-sectional study. Br J Dermatol 178(2):452-461. https://doi.org/10.1111/bjd.15813

Held E, Wolff C, Gyntelberg F, Agner T (2001) Prevention of workrelated skin problems in student auxiliary nurses: an intervention study. Contact Dermat 44(5):297-303

Ibler KS, Jemec GB, Agner T (2012) Exposures related to hand eczema: a study of healthcare workers. Contact Dermat 66(5):247-253. https://doi.org/10.1111/j.1600-0536.2011.02027.x

Jee SH, Wang JD, Sun CC, Chao YF (1986) Prevalence of probable kerosene dermatoses among ball-bearing factory workers. Scand J Work Environ Health 12(1):61-65

Jung PK et al (2014) The effect of work characteristics on dermatologic symptoms in hairdressers. Ann Occup Environ Med 26:13. https://doi.org/10.1186/2052-4374-26-13

Jungbauer FH, Lensen GJ, Groothoff JW, Coenraads PJ (2004a) Exposure of the hands to wet work in nurses. Contact Dermat 50(4):225-229. https://doi.org/10.1111/j.0105-1873.2004.0314.x

Jungbauer FH, van der Vleuten P, Groothoff JW, Coenraads PJ (2004b) Irritant hand dermatitis: severity of disease, occupational exposure to skin irritants and preventive measures 5 years after initial diagnosis. Contact Dermat 50(4):245-251. https://doi.org/10. 1111/j.0105-1873.2004.00347.x

Kartono F, Maibach HI (2006) Irritants in combination with a synergistic or additive effect on the skin response: an overview of tandem irritation studies. Contact Dermat 54(6):303-312

Kavli G, Moseng D (1987) Contact urticaria from mustard in fish-stick production. Contact Dermat 17(3):153-155

Keczkes K, Bhate SM, Wyatt EH (1983) The outcome of primary irritant hand dermatitis. Br J Dermatol 109(6):665-668

Keegel T, Moyle M, Dharmage S, Frowen K, Nixon R (2009) The epidemiology of occupational contact dermatitis (1990-2007): a systematic review. Int J Dermatol 48(6):571-578 
Kezic S, Visser MJ, Verberk MM (2009) Individual susceptibility to occupational contact dermatitis. Ind Health 47(5):469-478

Kiec-Swierczynska M, Wojtczak J (2000) Occupational ceramic fibres dermatitis in Poland. Occup Med (oxf, Engl) 50(5):337-342

Lan CC et al (2011) Hand dermatitis among university hospital nursing staff with or without atopic eczema: assessment of risk factors. Contact Dermat 64(2):73-79. https://doi.org/10.1111/j.16000536.2010.01813.x

Landeck L, Visser M, Kezic S, John SM (2012) Impact of tumour necrosis factor-alpha polymorphisms on irritant contact dermatitis. Contact Dermat 66(4):221-227. https://doi.org/10.1111/j. 1600-0536.2011.02045.x

Lazarov A, Nevo K, Pardo A, Froom P (2005) Self-reported skin disease in hydrotherapists working in swimming pools. Contact Dermat 53(6):327-331

Lee SW, Cheong SH, Byun JY, Choi YW, Choi HY (2013) Occupational hand eczema among nursing staffs in Korea: Self-reported hand eczema and contact sensitization of hospital nursing staffs. J Dermatol 40(3):182-187

Lindemayr H (1984) Eczema in hairdressers. Dermatosen in Beruf Und Umwelt Occup Environ 32(1):5-13

Livesley EJ, Rushton L, English JS, Williams HC (2002) Clinical examinations to validate self-completion questionnaires: dermatitis in the UK printing industry. Contact Dermat 47(1):7-13

Lund T, Flachs EM, Ebbehoj NE, Bonde JP, Agner T (2019) Wet work exposure: comparison of observed and self-reported data. Int Arch Occup Environ Health 92(3):317-326. https://doi.org/10. 1007/s00420-018-1383-7

Lushniak BD (2003) The importance of occupational skin diseases in the United States. Int Arch Occup Environ Health 76(5):325330. https://doi.org/10.1007/s00420-002-0417-2

Lysdal SH, Sosted H, Johansen JD (2012) Do hairdressers in Denmark have their hand eczema reported as an occupational disease? Results from a register-based questionnaire study. Contact Dermat 66(2):72-78. https://doi.org/10.1111/j.1600-0536.2011. 01997.x

Malkonen T et al (2009) A 6-month follow-up study of 1048 patients diagnosed with an occupational skin disease. Contact Dermat 61(5):261-268. https://doi.org/10.1111/j.1600-0536.2009. 01611.x

Malkonen T et al (2010) Long-term follow-up study of occupational hand eczema. Br J Dermatol 163(5):999-1006. https://doi.org/ 10.1111/j.1365-2133.2010.09987.x

McDonald JC, Beck MH, Chen Y, Cherry NM (2006) Incidence by occupation and industry of work-related skin diseases in the United Kingdom, 1996-2001. Occup Med (oxf, Engl) 56(6):398-405

Meding B (2000) Differences between the sexes with regard to workrelated skin disease. Contact Dermat 43(2):65-71

Meding B, Barregard L (2001) Validity of self-reports of hand eczema. Contact Dermat 45(2):99-103

Meding B, Lindahl G, Alderling M, Wrangsjo K, Anveden Berglind I (2013) Is skin exposure to water mainly occupational or nonoccupational? A population-based study. Br J Dermatol 168(6):12811286. https://doi.org/10.1111/bjd.12275

Meding B, Anveden Berglind I, Alderling M, Lindahl G, Wrangsjo K (2016) Water exposure-challenging differences between occupations. Contact Dermat 74(1):22-28. https://doi.org/10.1111/ cod. 12479

Mirabelli MC et al (2009) Metalworking exposures and persistent skin symptoms in the ECRHS II and SAPALDIA 2 cohorts. Contact Dermat 60(5):256-263. https://doi.org/10.1111/j.1600-0536. 2009.01525.x

Mirabelli MC et al (2012) Occupational risk factors for hand dermatitis among professional cleaners in Spain. Contact Dermat
66(4):188-196. https://doi.org/10.1111/j.1600-0536.2011. 02023.x

Moher D, Cook DJ, Eastwood S, Olkin I, Rennie D, Stroup DF (1999) Improving the quality of reports of meta-analyses of randomized controlled trials: the QUOROM Statement. Lancet (lond, Engl) 354(9193):1896-1900

Moher D, Liberati A, Tetzlaff J, Altman DG, Group P (2009) Preferred reporting items for systematic reviews and meta-analyses: the PRISMA statement. BMJ (clin Res Ed) 339:b2535. https://doi. org/10.1136/bmj.b2535

Mortz CG, Bindslev-Jensen C, Andersen KE (2014) Hand eczema in the odense adolescence cohort study on atopic diseases and dermatitis (TOACS): prevalence, incidence and risk factors from adolescence to adulthood. Br J Dermatol 171(2):313-323. https://doi.org/10.1111/bjd.12963

Nicholson PJ, Llewellyn D, English JS (2010) Evidence-based guidelines for the prevention, identification and management of occupational contact dermatitis and urticaria. Contact Dermat 63(4):177-186

Nielsen J (1996) The occurrence and course of skin symptoms on the hands among female cleaners. Contact Dermat 34(4):284-291

Nilsson E, Mikaelsson B, Andersson S (1985) Atopy, occupation and domestic work as risk factors for hand eczema in hospital workers. Contact Dermat 13(4):216-223

Pedersen LK, Held E, Johansen JD, Agner T (2005) Short-term effects of alcohol-based disinfectant and detergent on skin irritation. Contact Dermat 52(2):82-87

Petersen R, Sabroe S (1991) Irritative symptoms and exposure to mineral wool. Am J Ind Med 20(1):113-122

Rosen RH, Freeman S (1993) Prognosis of occupational contact dermatitis in New South Wales, Australia. Contact Dermat 29(2):88-93

Rothman KJ, Greenland S, Lash TL (2008) Modern epidemiology, Third, edition. Lippincott Williams \& Wilkins, Philadelphia

Rustemeyer T, von Hoogstraten IMW, von Blomberg BME, Gibbs S, Scheper RJ (2011) Mechanisms of irritant and allergic contact dermatitis. In: Johansen JD, Frosch PJ, Lepoittevin J-P (eds) Contact Dermatitis, 5th edn. Springer, Berlin, p 43

Schwensen JF, Menne T, Johansen JD (2014) The combined diagnosis of allergic and irritant contact dermatitis in a retrospective cohort of 1000 consecutive patients with occupational contact dermatitis. Contact Dermat 71(6):356-363. https://doi.org/10. 1111/cod.12288

Shah M, Lewis FM, Gawkrodger DJ (1996) Prognosis of occupational hand dermatitis in metalworkers. Contact Dermat 34(1):27-30

Skoet R, Olsen J, Mathiesen B, Iversen L, Johansen JD, Agner T (2004) A survey of occupational hand eczema in Denmark. Contact Dermat 51(4):159-166

Slodownik D, Lee A, Nixon R (2008) Irritant contact dermatitis: a review. Aust J Dermatol 49(1):1-9. https://doi.org/10.1111/j. 1440-0960.2007.00409.x

Slotosch CM, Kampf G, Loffler H (2007) Effects of disinfectants and detergents on skin irritation. Contact Dermat 57(4):235-241

Smit HA, Coenraads PJ, Lavrijsen AP, Nater JP (1992) Evaluation of a self-administered questionnaire on hand dermatitis. Contact Dermat 26(1):11-16

Sorensen JA, Clemmensen KK, Nixon RL, Diepgen TL, Agner T (2015) Tobacco smoking and hand eczema-is there an association? Contact Dermat 73(6):326-335. https://doi.org/10.1111/ cod. 12429

Stingeni L, Lapomarda V, Lisi P (1995) Occupational hand dermatitis in hospital environments. Contact Dermat 33(3):172-176

Stingeni L, Lapomarda V, Lisi P (1996) Undesirable effects from latex gloves in hospital health-care personnel. J Eur Acad Dermatol Venereol 7(1):44-48 
Tacke J, Schmidt A, Fartasch M, Diepgen TL (1995) Occupational contact dermatitis in bakers, confectioners and cooks. A populationbased study. Contact Dermat 33(2):112-117

Teo S, Teik-Jin Goon A, Siang LH, Lin GS, Koh D (2009) Occupational dermatoses in restaurant, catering and fast-food outlets in Singapore. Occup Med (oxf, Engl) 59(7):466-471. https://doi. org/10.1093/occmed/kqp034

Thyssen JP, Johansen JD, Linneberg A, Menne T (2010) The epidemiology of hand eczema in the general population-prevalence and main findings. Contact Dermat 62(2):75-87. https://doi.org/ 10.1111/j.1600-0536.2009.01669.x

Tiedemann D, Clausen ML, John SM, Angelova-Fischer I, Kezic S, Agner T (2015) Effect of glove occlusion on the skin barrier. Contact Dermat. https://doi.org/10.1111/cod.12470

Tsunoda M et al (2014) Skin irritation to glass wool or continuous glass filaments as observed by a patch test among human japanese volunteers. Ind Health 52(5):439-444

Turner S et al (2007) The incidence of occupational skin disease as reported to The Health and Occupation Reporting (THOR) network between 2002 and 2005. Br J Dermatol 157(4):713-722

Uter W, Pfahlberg A, Gefeller O, Schwanitz HJ (1998a) Prevalence and incidence of hand dermatitis in hairdressing apprentices: results of the POSH study Prevention of occupational skin disease in hairdressers. Int Arch Occup Environ Health 71(7):487-492

Uter W, Pfahlberg A, Gefeller O, Schwanitz HJ (1998b) Risk factors for hand dermatitis in hairdressing apprentices. Results of the 'Prevention of occupational skin disease in hairdressers' study. Derm Beruf Umwelt 46(4):151-158

Uter W, Pfahlberg A, Gefeller O, Schwanitz HJ (1999a) Hand dermatitis in a prospectively-followed cohort of hairdressing apprentices: final results of the POSH study. Prevention of occupational skin disease in hairdressers. Contact Dermat 41(5):280-286

Uter W, Pfahlberg A, Gefeller O, Schwanitz HJ (1999b) Risk of hand dermatitis among hairdressers versus office workers. Scand J Work Environ Health 25(5):450-456
Vermeulen R, Kromhout H, Bruynzeel DP, de Boer EM, Brunekreef B (2001) Dermal exposure, handwashing, and hand dermatitis in the rubber manufacturing industry. Epidemiology 12(3):350-354

Vester L, Thyssen JP, Menne T, Johansen JD (2012) Consequences of occupational food-related hand dermatoses with a focus on protein contact dermatitis. Contact Dermat 67(6):328-333

Visser MJ et al (2013) Impact of atopic dermatitis and loss-of-function mutations in the filaggrin gene on the development of occupational irritant contact dermatitis. Br J Dermatol 168(2):326-332. https://doi.org/10.1111/bjd.12083

Visser MJ et al (2014a) Filaggrin loss-of-function mutations and atopic dermatitis as risk factors for hand eczema in apprentice nurses: part II of a prospective cohort study. Contact Dermat 70(3):139 150. https://doi.org/10.1111/cod.12139

Visser MJ, Verberk MM, van Dijk FJ, Bakker JG, Bos JD, Kezic S (2014b) Wet work and hand eczema in apprentice nurses; part I of a prospective cohort study. Contact Dermat 70(1):44-55. https://doi.org/10.1111/cod.12131

Weistenhofer W, Wacker M, Bernet F, Uter W, Drexler H (2015) Occlusive gloves and skin conditions: is there a problem? Results of a cross-sectional study in a semiconductor company. Br J Dermatol 172(4):1058-1065

Weistenhofer W, Uter W, Drexler H (2017) Protection during production: problems due to prevention? Nail and skin condition after prolonged wearing of occlusive gloves. J Toxicol Environ Health Part A 80(7-8):396-404. https://doi.org/10.1080/10937 404.2017.1304741

Publisher's Note Springer Nature remains neutral with regard to jurisdictional claims in published maps and institutional affiliations. 